\title{
Acción del agua de mar sobre un cemento portland de alta resistencia inicial, sobre un cemento portland resistente a los sulfatos y sobre un cemento portland: influencia de la adición de escoria. Estudio por DRX
}

\author{
L'action de l'eau de mer sur un ciment portland \\ à haute résistance initiale, sur un ciment portland \\ résistant aux sulfates et sùr un ciment portland \\ ordinaire: influence de l'addition de laitier. \\ Etude par DRX
}

DEMETRIO GASTAR-TEBAR Y JOSE LUIS SAGRERA-MORENO

IETCC/CSIC

Fecha de Recepción: 14-VII-87

Serrano Galvache s/n. 28033 - Madrid/España

\begin{abstract}
RESUMEN
En este trabajo se estudia, por medio de difracción de rayos $X$, la evolución de las características estructurales de los compuestos cristalinos de la fracción enriquecida (cemento hidratado-atacado) extraída de uno de los prismas de mortero $(1: 3)$ de $1 \times 1 \times 6 \mathrm{~cm}$ de cada una de las series de probetas fabricadas con tres cementos portland (alta resistencia inicial, cemento 1; resistente a los sulfatos, cemento 2, y normal, cemento 3) y con las mezclas cemento $(1,2$ y 3$)$ /escoria $=85 / 15-65 / 35$ 40/60 y 30/70 (en peso), sometidas a la acción del agua de mar artificial (ASTM D 1141-75) durante 56 - 90 - 180 y 360 dias, después del período de curado (1 día en cámara húmeda y 21 dias bajo agua potable filtrada); del mismo modo, se estudia por DRX la composición estructural de la nueva fase sólida formada en el agua de mar artificial en donde han estado sumergidas las probetas de mortero.
\end{abstract}

En los DRX de la nueva fase sólida se han identificado los picos de los compuestos cristalinos calcita, aragonito y brucita, de acuerdo con las condiciones del sistema y, de un modo especial, de las mezclas cemento/escoria utilizadas en la fabricación de las probetas de mortero. Los picos de la brucita, únicamente, se han identificado en la fase sólida formada en el agua de mar artificial en donde han estado sumergidas las probetas de mortero fabricadas con cualquiera de los cementos estudiados y con las mezclas de estos cementos con el $15 \%$ de escoria (en peso).

En los DRX de la fracción enriquecida (cemento hidratado-atacado) se han identificado, con intensidad variable, los picos de los compuestos cristalinos ettringita, brucita y calcita en todos los DRX y los picos de la sal de Friedel, yeso y portlandita en determinados DRX. En este trabajo, se ha puesto de manifiesto la influencia que ejerce la adición de escoria, así como el tiempo de conservación-ataque, en la formación y eliminación de los compuestos mencionados.

\section{RESUME}

Dans ce travail on étudie, au moyen de DRY, l'evolution des caractéristiques estructurelles des composants cristallins de la fraction enrichie (ciment hydraté-ataqué) extrait d'un des prismes de mortier $(1: 3)$ de $1 \times 1 \times 6 \mathrm{~cm}$ de chacune des séries fabriquées avec trois ciments portland (à haute résistance initiale, ciment 1 , résistant aux sulfates, ciment 2, et ordinaire, ciment 3 ) et avec les mélanges ciment $(1,2$ et 3)/laitier $=85 / 15-65 / 35$ 40/60 y 30/70 (en poids) soumises à l'action de l'eal de mer artificielle (ASTM D174 -75) pendant $56-90-180 \mathrm{e}$ 360 jours, après la période de conservation (1 jour en chambre humide et 21 jours sous eau douce): de même. on étudie au moyen DRX ia composition structurelle de la nouvelle phase solide formée dans l'eau de mer artificielle où les éprouvettes de mortier ont été immergées.

Dans les DRX de la nouvelle phase solide les pics des composants cristallins calcite, aragonite et brucite ont été identifiés, suivant les conditions du système et de façon specialle des mélanges ciment/laitier utilisés pour élaborer les éprouvettes de mortier. Les pics du brucite uniquement ont été detectés dans la phase solide formée dans l'eau de mer artificielle où ont été immergées les éprouvettes fabriquées avec quelqu'un des ces ciments et avec les mélanges de ces ciments avec $15 \%$ de laitier (en poids).

Dans les $D R X$ de la fraction enrichie (ciment hydraté-attaquée) on a identifié les pics des composants cristallins ettringite, brucite et calcite dans tous les DRX, avec intensité variable, et les pics de sel de Friedel, gypse et portlandite dans quelq'uns des DRX. Dans ce travail, l'influence exercée par l'addition de laitier et par le temps conservation-attaque dans la formation ou l'elimination des composants mentionnés, a été observée. 


\section{INTRODUCCION}

Con objeto de ampliar el conocimiento sobre el mecanismo de las reacciones que tienen lugar cuando los cementos portland industriales hidratados - de características estructurales distintas - y sobre todo de sus mezclas con adiciones naturales y artificiales, se someten a la acción de disoluciones agresivas se ha realizado este trabajo, que forma parte de un Programa de Investigación del IETcc a desarrollar a largo plazo, tanto a escala de laboratorio como a escala real.

En otros trabajos (1) (2) (3) (4) (5) (6), se estudia el comportamiento mecánico-resistente de uno de los cementos objeto de este trabajo (cemento 2), cuando diversas series de probetas de mortero y de hormigón se someten a la acción de distintas disoluciones agresivas (1) (2), la variación de la concentración iónica del agua de mar en donde han estado sumergidas las probetas de mortero hechas con dos de estos cementos (cemento 1 y cemento 2) -y con sus mezclas con la escoria de este trabajo (cemento/escoria $=85 / 15,65 / 35,40 / 60$ y $30 / 70$, en peso) - (3) y de otras disoluciones agresivas que han atravesado los lechos elaborados con uno de estos cementos (cemento 2), así como la variación de las características estructurales de dicho cemento (4) (5) (6).

\section{PARTE EXPERIMENTAL}

En este trabajo se estudia por DRX la evolución de las características estructurales de los compuestos cristalinos de la fracción enriquecida (cemento hidratado-atacado) extraida de uno de los prismas de mortero de cada serie fabricada con los tres cementos, que se citan a continuación, y con las mezclas cemento $(1,2$ y 3$)$ /escoria $=85 / 15-65 / 35$ $40 / 60$ y $30 / 70$ (en peso), sometidas a la acción del agua de mar artificial durante 56 - 90 - 180 y 360 días, después del período de curado (1 día en cámara húmeda y 21 días bajo agua potable filtrada); asimismo, se estudia por DRX la composición estructural de la nueva fase sólida formada en el agua de mar artificial en donde han estado sumergidas las probetas de mortero.

\subsection{Materiales utilizados}

\subsubsection{Cementos}

Se han utilizado tres cementos portland industriales (de alta resistencia inicial, resistente a los sulfatos y ordinario, cementos 1 - 2 y 3 , respectivamente), cuya composición

\section{INTRODUCTION}

A l'objet d'élargir la connaissance sur le mécanisme des réactions qui ont lieu lorsque les ciments portland industriels hydratés - de caracteristiques structurelles différentes- et surtout de leurs mélanges avec ajouts naturelles et artificielles, soumis à l'action de solutions agréssives, nous avons réalisé ce travail, qui fait partie d'un Projet de Recherche de l'IETCC, à développer à long terme, aussi bien à échelle de laboratoire qu'à échelle réelle.

Dans d'autres travaux (1) (2) (3) (4) (5) (6), nous étudions le comportement mécanique-résistant d'un des ciments qui font l'objet de ce travail (ciment 2), lorsque diverses séries d'éprouvettes de mortier et de béton sont soumises á l'action de différentes solutions agressives (1) (2), la variation de la concentration ionique de l'eau de mer artificielle où l'on a mis en immersion les éprouvettes de mortier élaborées avec deux de ces ciments (ciment 1 et ciment 2) -et avec leurs mélanges avec le laitier de ces travaux (ciment/laitier $=85 / 15,65 / 35,40 / 60$ et $30 / 70$, en poids) - (3) et d'autres solutions agressives qui ont traversé les lits élaborés avec un de ces ciments (ciment 2), ainsi que la variation des caractéristiques structurelles de ce ciment (4) (5) (6).

\section{PARTIE EXPERIMENTALE}

Dans ce travail nous étudions au moyen de $D R X$ l'évolution des caracteristiques de composants cristallins de la fraction enrichie (ciment hydraté-attaqué) extraite d'un des prismes de mortier de chacune des séries fabriquées avec les trois ciments mentionnés ci-dessus, et avec les mélanges ciment 1,2 et 3)/laitier $=85 / 15,65 / 35,40 / 60$ et $30 / 70$ (en poids), soumises à l'action de l'eau de mer artificielle pendant $56,90,180$ et 360 jours suivant 2.2; de même, nous étudions au moyen de DRX la composition structurelle de la nouvelle phase solide formé dans l'eau de mer artificielle où les éprouvettes de mortier ont été immergées.

\subsection{Matériaux utilisés}

\subsubsection{Ciments}

Nous avons utilisé trois ciments portland industriels (à haute résistance initiale, résistant aux sulfates et normal, ciments 1, 2 et 3 , respectivement) dont la composition 
química y potencial calculada (Bogue), así como la superficie específica, se encuentran en la tabla 1. En la figura 1 se incluyen los DRX de las fases cristalinas correspondientes a los aluminatos de los residuos en ácido salicílico-metanol de dichos cementos.

\subsubsection{Escoria}

Se ha empleado la escoria cuyo análisis químico y diagrama de difracción de rayos $X$ se encuentra en la tabla 1 y fig. 2 , respectivamente.

\subsubsection{Agua de mar artificial}

El agua de mar artificial se ha preparado según el punto 6 de la norma ASTM 1141-75. El contenido de los iones, que se citan a continuación, y el pH determinados experimentalmente, es el siguiente: $\mathrm{Ca}(\mathrm{II})=0,521 \mathrm{~g} / \mathrm{l} ; \mathrm{Mg}$ (II) $=1,347 \mathrm{~g} / \mathrm{l}$; $\mathrm{SO}_{4}(\mathrm{II})=2,928 \mathrm{~g} / \mathrm{l} ; \mathrm{Cl}(\mathrm{I})=19,585 \mathrm{~g} / \mathrm{l}$ y $\mathrm{pH}=6,5$. chimique et potentielle calculée (Bogue), ainsi que la surface spécifique, se trouvent dans le tableau 1. Dans la fig. 1 sont représentées les DRX des phases cristallines correspondantes aux aluminates de l'insoluble en acide salicylique-méthanol de ces ciments.

\subsubsection{Laitier}

L'analyse chimique et le diagramme de diffraction de rayons $X$ du laitier employé, se trouvent dans le tableau 1 et dans la fig. 2, respectivement.

\subsubsection{Eau de mer artificielle}

L'eau de mer artificielle a été préparée d'après le point 6 de la Norme ASTM D 114i-75. La teneur en ions, mentionnés ci-après, et le $p H$ déterminés experimentalement, est le suivant: Ca $(I I)=0,521 \mathrm{~g} / \mathrm{l} ; \mathrm{Mg}(\mathrm{II})=1,374 \mathrm{~g} / \mathrm{l}$; $\mathrm{SO}_{4}(\mathrm{II})=2,928 \mathrm{~g} / \mathrm{l} ; \mathrm{Cl}(\mathrm{l})=19,585 \mathrm{~g} / \mathrm{l} \mathrm{et}$ $p H=6,5$.

TABLA 1

TABLEAU 1

1. Análisis químico (\% e.p.) Analyse chimique (\% e.p.)

\begin{tabular}{|l|r|r|r|r|}
\hline \multirow{2}{*}{$\begin{array}{c}\text { Determinaciones } \\
\text { Déterminations }\end{array}$} & \multicolumn{3}{|c|}{ Cementos (ciments) } & \multirow{2}{*}{ Escoria (Laitier) } \\
\cline { 2 - 5 } & $\mathbf{1}$ & $\mathbf{2}$ & $\mathbf{3}$ & 0,4 \\
P.F. & 0,4 & 1,1 & 2,7 & 0,0 \\
$\mathrm{R} . \mathrm{I}$. & 3,1 & 0,2 & 0,1 & 35,2 \\
$\mathrm{SiO}_{2}$ & 19,3 & 22,0 & 18,5 & 0,7 \\
$\mathrm{Fe}_{2} \mathrm{O}_{3}$ & 3,9 & 4,1 & 2,6 & 17,0 \\
$\mathrm{Al}_{2} \mathrm{O}_{3}$ & 6,2 & 1,8 & 5,3 & 37,3 \\
$\mathrm{CaO}$ & 61,1 & 67,9 & 62,0 & 6,3 \\
$\mathrm{MgO}$ & 1,5 & 0,5 & 3,1 & 0,0 \\
$\mathrm{SO}$ & 4,1 & 2,3 & 4,6 & 0,8 \\
$\mathrm{Mn}$ (II) & n.d. & n.d. & - & - \\
$\mathrm{CaO}$ libre & 1,0 & 1,8 & & \\
n.d. $=$ pas dosé. & & & & \\
\hline
\end{tabular}

2. Composición potencial (Bogue), $\%$ Composition potentielle (Bogue), \%

\begin{tabular}{|l|r|r|r|r|}
\hline $\mathrm{C}_{3} \mathrm{~S}$ & 39,2 & 75,6 & 56,4 & - \\
$\mathrm{C}_{2} \mathrm{~S}$ & 25,7 & 6,1 & 10,5 & - \\
$\mathrm{C}_{3} \mathrm{~A}$ & 9,9 & 0,0 & 9,7 & - \\
$\mathrm{C}_{4} \mathrm{AF}$ & 12,0 & 10,8 & 7,9 & - \\
\hline
\end{tabular}

3. Superficie específica (Blaine)

Surface spécifique (Blaine)

\begin{tabular}{|l|l|l|l|l|}
\hline $\mathrm{cm}^{2} / \mathrm{g}$ & 5.313 & 3.553 & 3.748 & - \\
\hline
\end{tabular}




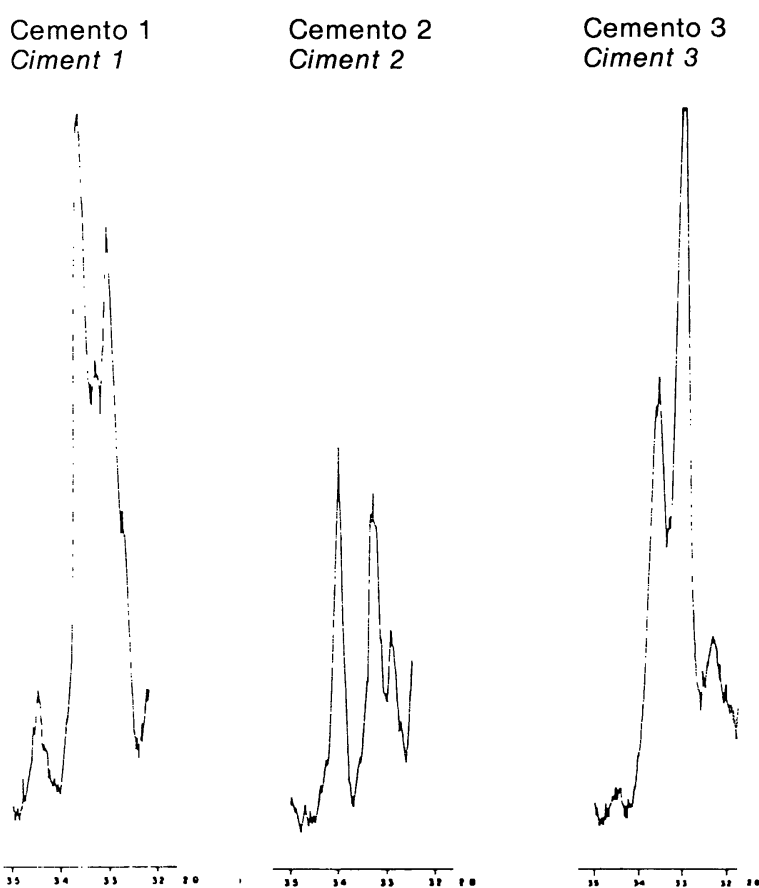

Fig. 1.-Cementos. DRX de los residuos en ácido salicílico-metanol (RSM)

Fig. 1.-Ciments. DRX RSM.

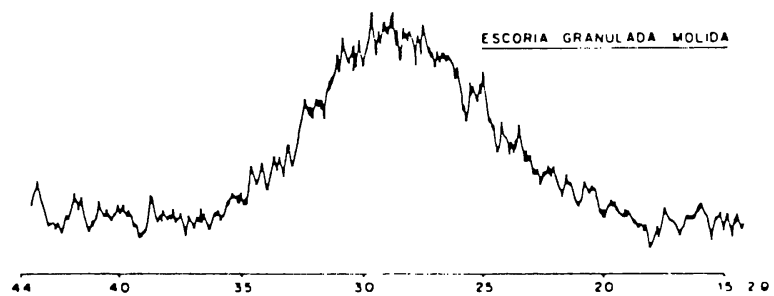

Fig. 2.-Escoria. Diagrama de difracción de rayos $X$.

Fig. 2.-Laitier. DRX.

\subsection{Preparación, curado y conservación de las probetas de mortero $(1: 3)$}

Con cada uno de los cementos se han preparado las siguientes mezclas cemento/escoria $=85 / 15-65 / 35-40 / 60$ y $30 / 70$ (en peso), que se han utilizado para elaborar las probetas de mortero $(1: 3)$ de $1 \times 1 \times 6 \mathrm{~cm}$, elaboración que se ha hecho como se señala en (7); la relación a/c ha sido 0,6 . Se han curado 1 día en cámara húmeda, a $20 \pm 1^{\circ} \mathrm{C}$, con una humedad relativa superior al $90 \%$ y, a continuación, bajo agua potable filtrada durante 21 días; posteriormente, se han sumergido 12 probetas/1 serie/cemento o mezcla/1 edad en $800 \mathrm{ml}$ de agua potable filtrada o en agua de mar artificial durante $56-90-180-360$ días.

\subsection{Preparación de la fase sólida}

La nueva fase sólida, formada en el agua de mar artificial en donde han estado sumergidas las probetas de mortero durante 56 - 90 - 180 y 360 días, se ha separado por filtración, una vez extraídas dichas probetas de mortero, y se ha secado con una corriente de nitrógeno. A continuación, se han determinado por DRX los compuestos cristalinos que existen (figs. 3.1 a $3.5 ; 4.3$ a 4.5 y 5.1 a 5.5$)$.

\subsection{Préparation, curé et conservation des éprouvettes de mortier $(1: 3)$}

Avec chacun des ciments nous avons préparé les mélanges suivants: ciment/laitier $=85 / 15$, $65 / 35,40 / 60$ et $30 / 70$ (en poids) qui ont été utilisés pour élaborer les éprouvettes de mortier (1:3) de $1 \times 1 \times 6 \mathrm{~cm}$, élaboration menée à bout comme en (7); la relation e/c a été 0,6 . Elles on été curées en chambre humide pendant 1 jour à $20 \pm 1^{\circ} \mathrm{C}$, avec une humidité relative supérieure à $90 \%$, après, sous eau douce pendant 21 jours; par la suite, 12 éprouvettes/1 série/ciment ou mélange/1 âge, ont été immergées dans $800 \mathrm{ml}$ d'eau douce ou dans d l'eau de mer artificielle pendant $56,90,180,360$ jours.

\subsection{Préparation de la phase solide}

La nouvelle phase solide formée dans l'eau de mer artificielle où les éprouvettes de mortier ont été immergées pendant 56,90, 180 et 360 jours a été séparée par filtration, les éprouvettes de mortier ayant été extraites auparavant, et les ayant séché dans un courant d'azote. Les composants cristallins existants ont été déterminés para la suite au moyen de DRX (figs. 3.1 à $3.5 ; 4.1$ à 4.5 et 5.1 à 5.5). 


\subsection{Preparación de la fracción enriquecida}

De uno de los prismas de mortero de cada serie de probetas, una vez extraídas del agua de mar artificial en donde han estado durante los períodos de tiempo mencionados y desecadas en un recinto aislado de la atmósfera, se ha separado la casi totalidad de la fracción correspondiente a la arena por disgregación mecánica y con ayuda de un tamiz de $88 \mu \mathrm{m}$. A continuación, se han determinado por DRX los compuestos cristalinos que existen (figs. 6.1 a $6.5 ; 7.1$ a 7.5 y 8.1 a 8.5 ) en la fracción restante.

\section{RESULTADOS OBTENIDOS}

Los diagramas de difracción de rayos $X$ de la
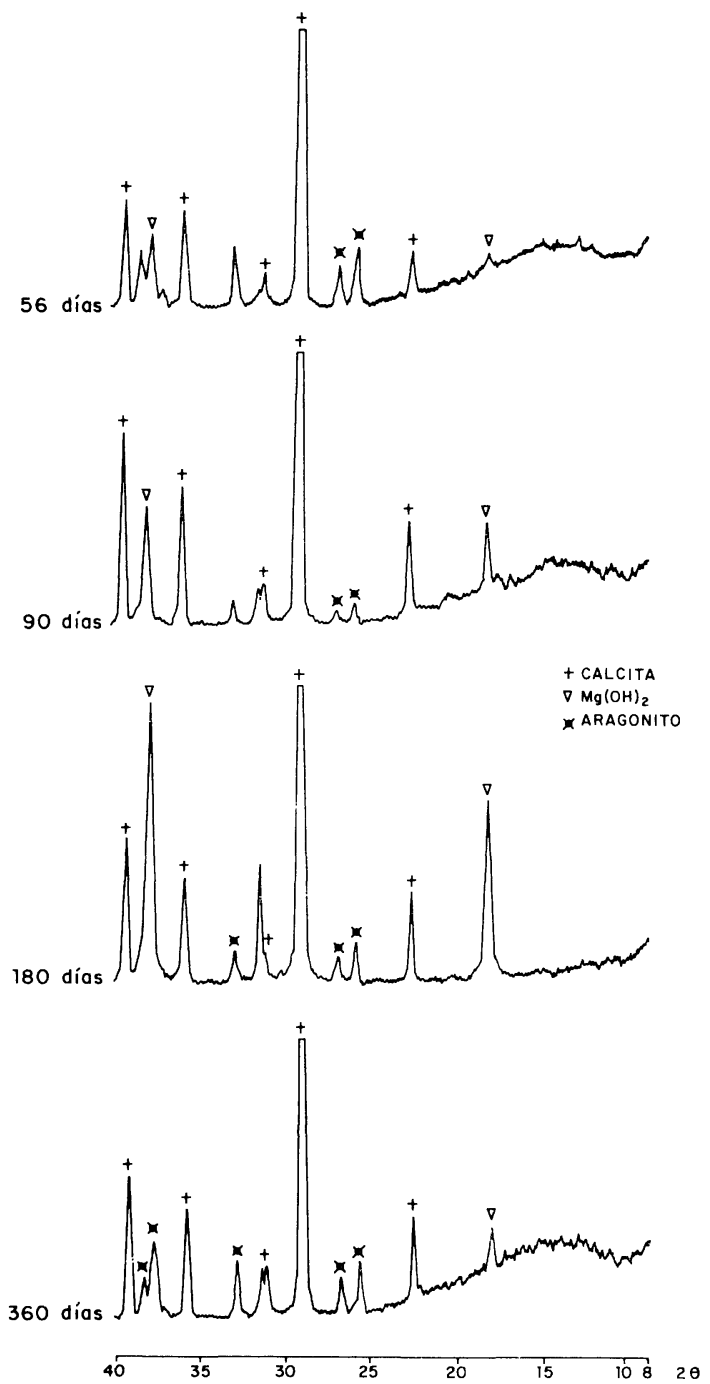

Fig. 3.1.-Sistema: cemento 1/escoria-agua de mar artificial.

Mezcla: cemento $1 /$ escoria $=100 / 0$ (en peso).

DRX de la nueva fase sólida.

Fig. 3.1.-Système: ciment 1/laitier-eau de mer artificielle.

Mélange: ciment $1 /$ laitier $=100 / 0$ (e.p.).

DRX de la nouvelle phase solide.

\subsection{Préparation de la fraction enrichie}

De l'un des prismes de mortier de chaque série d'éprouvettes, ayant auparavant extrait celles-ci de l'eau de mer artificielle où elles ont été immergées pendant les périodes indiquées, et séchées dans une enceinte isolée de l'atmosphère, nous avons séparé le presque totalité de la fraction correspondante au sable par disgrégation mécanique et avec l'aide d'un tamis de $88 \mu \mathrm{m}$. Les composants cristallins ont été ensuite déterminés (figs. 6.1 à $6.5 ; 7.1$ à 7.5 et 8.1 à 8.5) au moyen de DRX dans la fraction qui reste.

\section{RESULTATS OBTENUS}

Les diagrammes de diffraction de rayons $X$ de
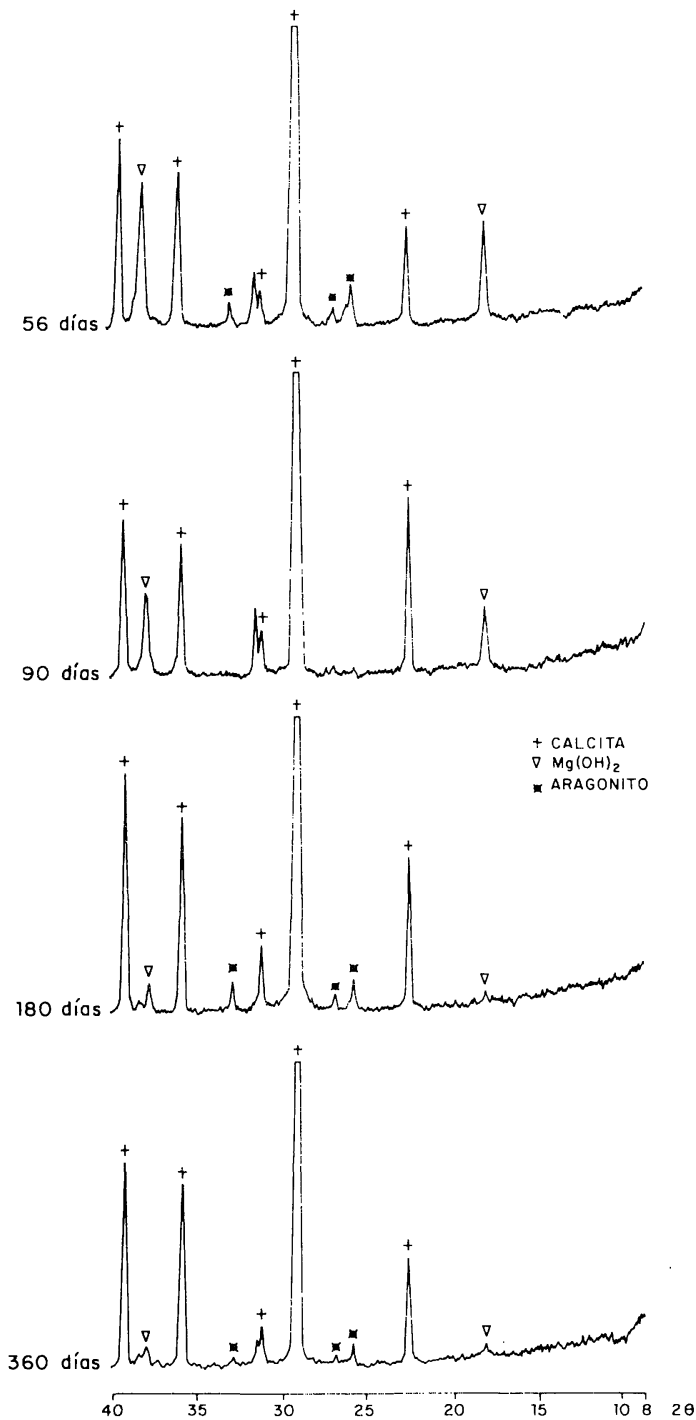

Fig. 3.2.- Sistema: cemento 1/escoria-agua de mar artificial.

Mezcla: cemento $1 /$ escoria $=85 / 15$ (en peso). DRX de la nueva fase sólida.

Fig. 3.2.-Système: ciment 1/laitier-eau de mer artificielle.

Mélange: ciment $1 /$ laitier $=85 / 15$ (e.p.).

DRX de la nouvelle phase solide. 
nueva fase sólida y de las fracciones enriquecidas se encuentran en las figuras 3.1 a $3.5,4.1$ a 4.5 y 5.1 a 5.5 , los primeros, y en las figuras 6.1 a $6.5,7.1$ a 7.5 y 8.1 a 8.5 , los segundos.

\section{INTERPRETACION DE RESULTADOS}

\subsection{Estudio de la nueva fase sólida}

En los diagramas de difracción de rayos $X$ de la fase sólida formada en el agua de mar artificial en donde han estado sumergidas las distintas series de probetas de mortero (1:3) hechas con los cementos 1,2 y 3 , así como con las mezclas de dichos cementos con un $15 \%$ de escoria, en peso, durante 56 - 90 -

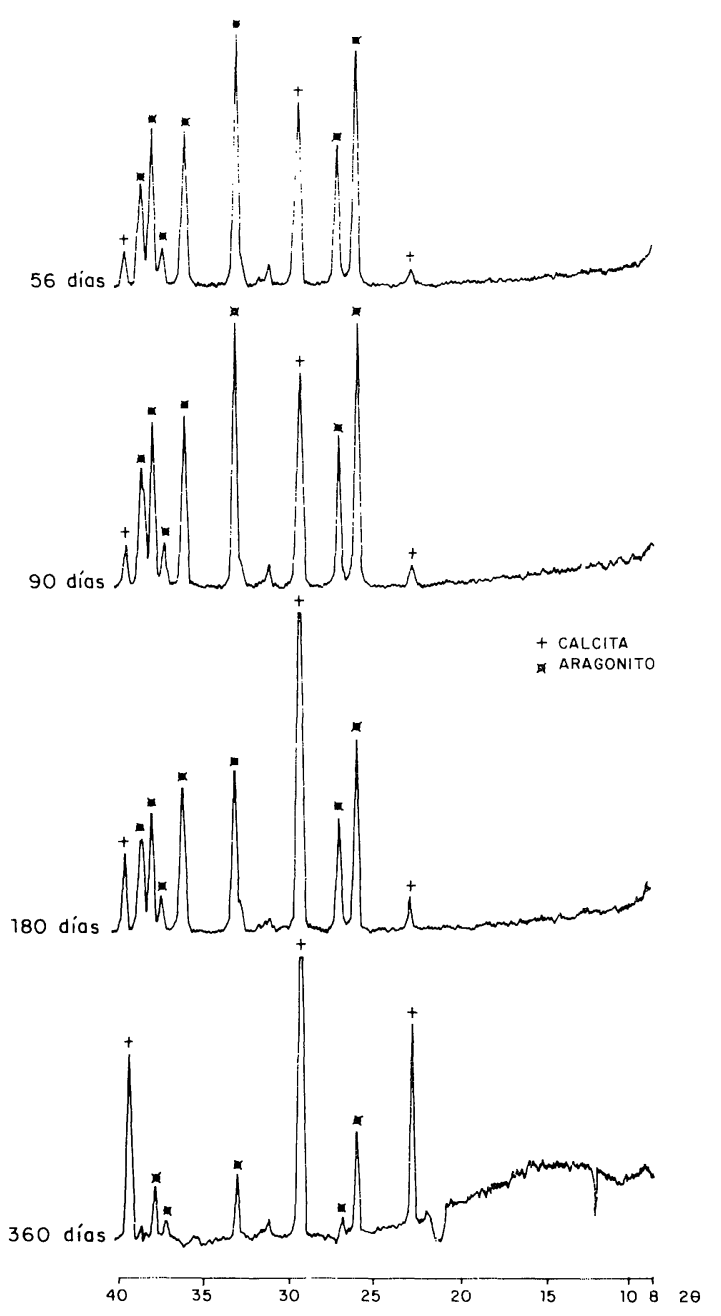

Fig. 3.3.-Sistema: cemento 1/escoria-agua de mar artificial.

Mezcla: cemento $1 /$ escoria $=65 / 35$ (en peso).

DRX de la nueva fase sólida.

Fig. 3.3.-Système: ciment 1/laitier-eau de mer artificielle.

Mélange: ciment $1 /$ laitier $=65 / 35$ (e.p.)

DRX de la nouvelle phase solide. la nouvelle phase solide et des fractions enrichies se trouvent dans les figs. 3.1 à 3.5 , 4.1 à 4.5 et 5.1 à 5.5 les premiers, et dans les figs. 6.1 à $6.5,7.1$ à 7.5 et 8.1 à 8.5 les seconds.

\section{INTERPRETATION DES RESULTATS}

\subsection{Etude de la nouvelle phase solide}

Dans les diagrammes de diffraction de rayons $X$ de la phase solide formée dans l'eau de mer artificielle où ont été immergées les différentes séries d'éprouvettes de mortier (1:3), fabriquées avec les ciments 1,2 et 3 , ainsi que avec les mélanges de ces ciments avec $15 \%$ de laitier, en poids, pendant $56,90,180$ et 360
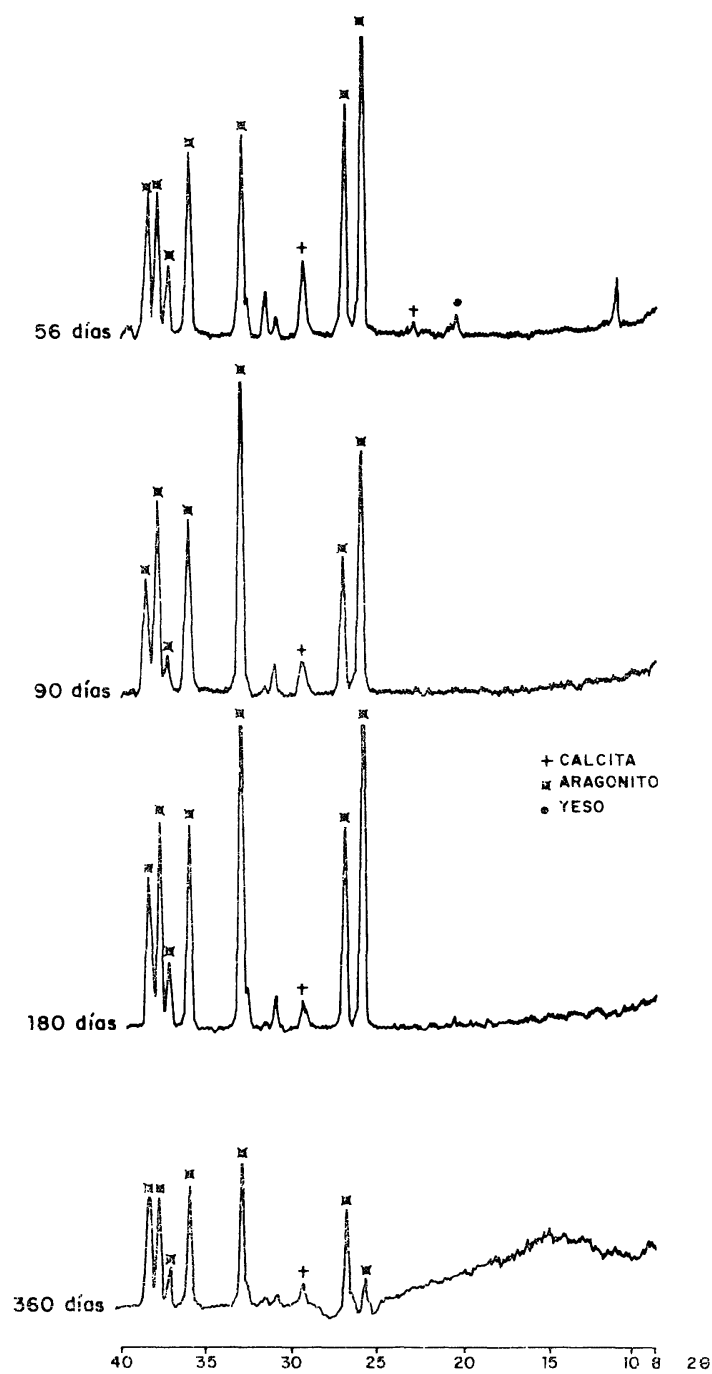

Fig. 3.4.-Sistema: cemento 1/escoria-agua de mai artificial.

Mezcla: cemento $1 /$ escoria $=40 / 60$ (en peso) DRX de la nueva fase sólida.

Fig. 3.4.-Système: ciment 1/laitier-eau de mer artificielle.

Mélange: ciment $1 /$ laitier $=40 / 60$ (e.p.)

DRX de la nouvelle phase solide. 
180 y 360 días (períodos de tiempo estudiados por el momento), se han identificado los picos de los compuestos cristalinos calcita, aragonito y brucita (figs. 3.1 y $3.2,4.1$ y $4.2,5.1$ y 5.2), mientras que en los medios (agua de mar artificial) en donde se han conservado, durante los mismos períodos de tiempo, las series de probetas fabricadas con las mezclas cemento $(1,2$ ó 3$) /$ escoria $=$ $=65 / 35-40 / 60$ y $30 / 70$ (en peso), únicamente, se han detectado los picos de los compuestos cristalinos calcita y aragonito (figs. 3.3 a $3.5,4.3$ a 4.5 y 5.3 a 5.5 ).

El Ca (II) presente en el agua de mar artificial $\left(1,30 \times 10^{-2}\right.$ moles/litro) ha experimentado, en todos los casos estudiados, un incremento debido, fundamentalmente, a la disolución de

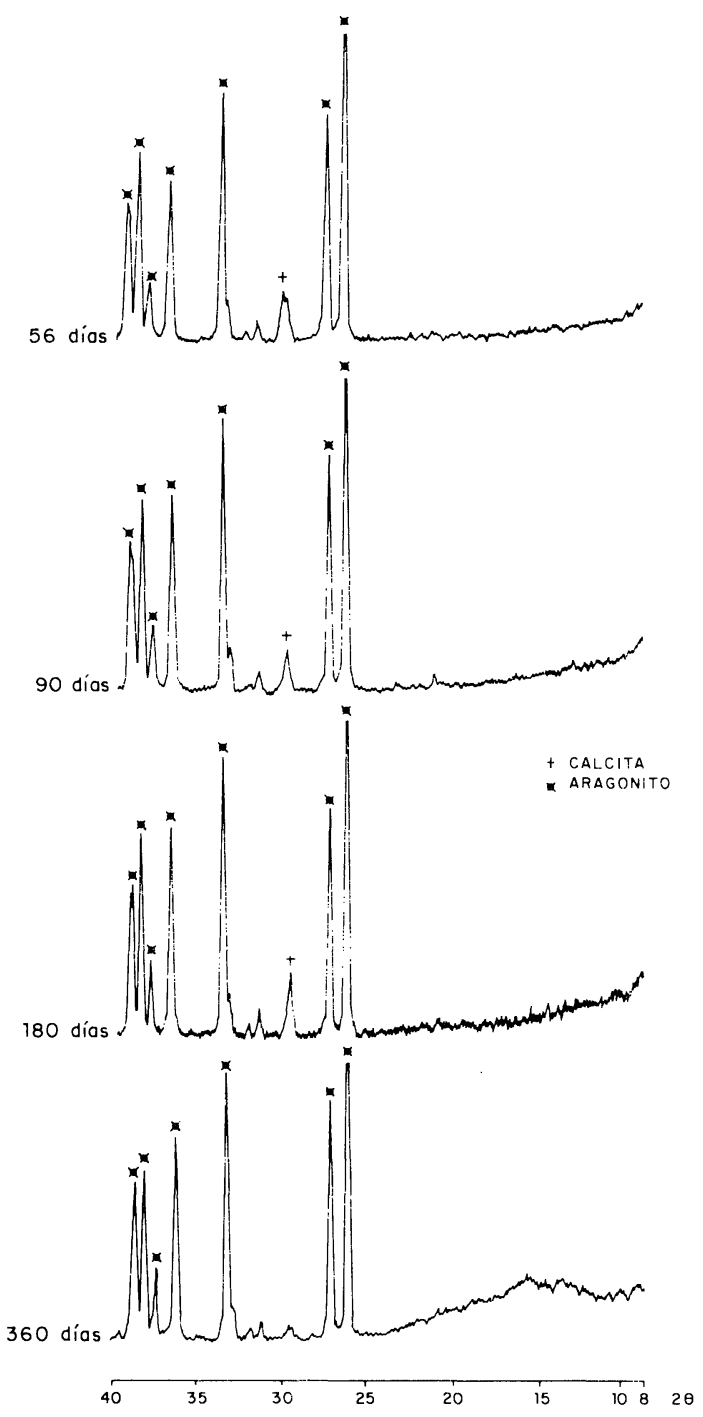

Fig. 3.5.-Sistema: cemento 1/escoria-agua de mar artificial.

Mezcla: cemento $1 /$ escoria $=30 / 70$ (en peso).

DRX de la nueva fase sólida.

Fig. 3.5.-Système: ciment 1/laitier-eau de mer artificielle.

Mélange: ciment 1/laitier $=30 / 70$ (e.p.).

$D R X$ de la nouvelle phase solide. jours (périodes de temps étudiées jusqu'ici), les pics des composants cristallins calcite, aragonite et brucite ont été identifiés (figs. 3.1 et 3.2, 4.1 et 4.2, 5.1 et 5.2), tandis que dans les solutions (eau de mer artificielle) oú furent immergées, pendant les mêmes périodes de temps, les séries d'éprouvettes élaborées avec les mélanges ciment (1,2 ou 3)/laitier $=65 / 35$ $40 / 60$ et $30 / 70$ (en poids) uniquement les pics des composants cristallins calcite et aragonite ont été detectés (figs. 3.3 à 3.5, 4.3 à 4.5 et 5.3 à 6.5 ).

Le Ca (II) présent dans l'eau de mer artificielle $\left(1,30 \times 10^{-2}\right.$ moles/litre $)$ a expérimenté, dans tous les cas étudiés, une augmentation due fondamentalement à la dissolution d'une partie 
parte del $\mathrm{Ca}(\mathrm{OH})_{2}$ formado durante las reacciones de hidratación de la fracción clínker del cemento, según el equilibrio $(A)$ : du $\mathrm{Ca}(\mathrm{OH})_{2}$ formé pendant les réactions d'hydratation de la fraction clinker du ciment, d'après l'équilibre (A):

$$
\begin{aligned}
& \mathrm{H}_{2} \mathrm{O} \quad \mathrm{H}_{2} \mathrm{O} \\
& \mathrm{Ca}(\mathrm{OH})_{2} \text {.sólido } \rightleftharpoons \mathrm{Ca}(\mathrm{OH})_{2} \text {.disuelto } \rightleftharpoons \mathrm{Ca}(\mathrm{II})+2 \mathrm{OH}(\mathrm{I}) \\
& \mathrm{H}_{2} \mathrm{O} \quad \mathrm{H}_{2} \mathrm{O} \\
& \text { mer mer } \\
& \mathrm{Ca}(\mathrm{OH})_{2} \text {.solide } \rightleftharpoons \mathrm{Ca}(\mathrm{OH})_{2} \text {.dissout } \rightleftharpoons \mathrm{Ca}(\mathrm{II})+2 \mathrm{OH}(\mathrm{I})
\end{aligned}
$$

produciendo un aumento de la basicidad del medio $\mathrm{y}$, por consiguiente, del valor del $\mathrm{pH}$, el cual ha pasado de 6,5 a valores superiores a 11 y a 10,6 en los medios en donde han estado sumergidas las series de probetas de mortero hechas con cemento 1, 2 ó 3 y con

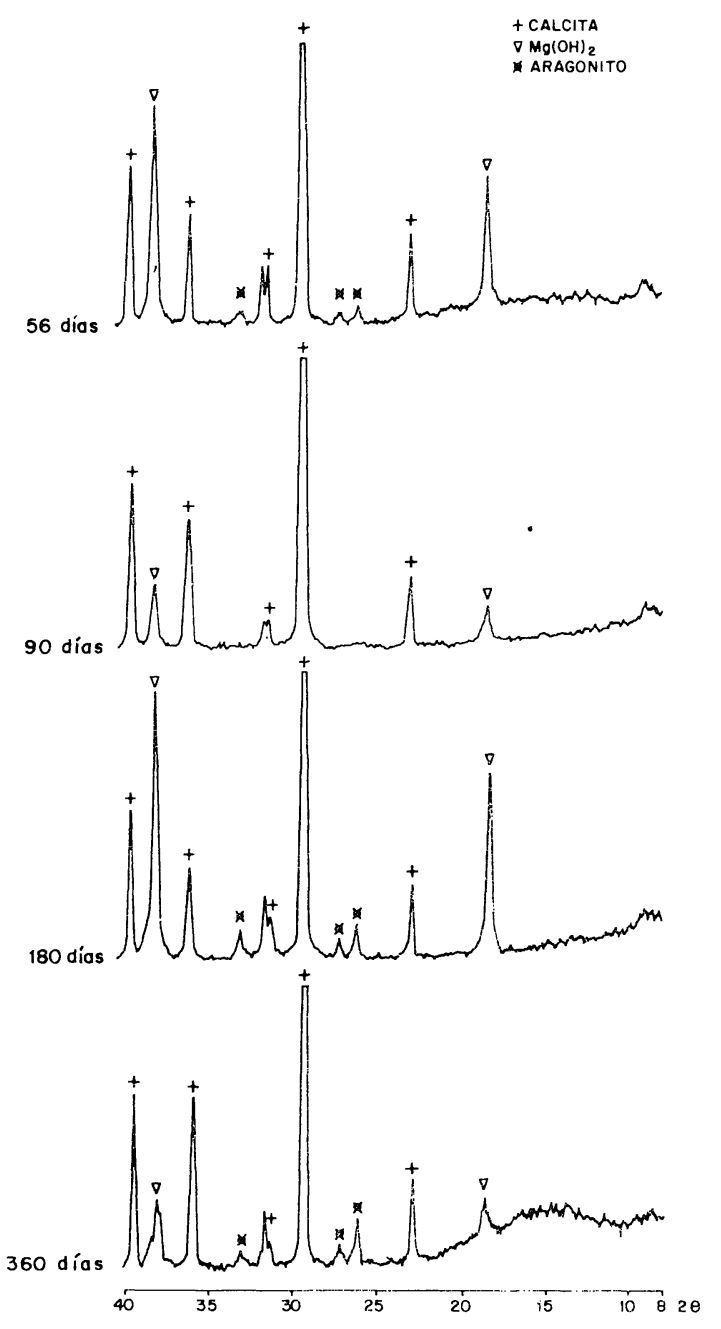

Fig. 4.2.-Sistema: cemento 2 /escoria-agua de mar artificial.

Mezcla: cemento 2/escoria $=85 / 15$ (en peso).

DRX de la nueva fase sólida.

Fig. 4.2.-Système: ciment 2/laitier-eau de mer artificielle.

Mélange: ciment 2/laitier $=85 / 15$ (e.p.).

DRX de la nouvelle phase solide. produisant une augmentation de basicité de la solution et, par conséquent, de la valeur $d u \mathrm{pH}$ qui est passée de 6,5 à des valeurs supérieures à 11 et à 10,6 dans les solutions où les séries d'éprouvettes de mortier élaborées avec ciment 1, 2 ou 3 et avec les

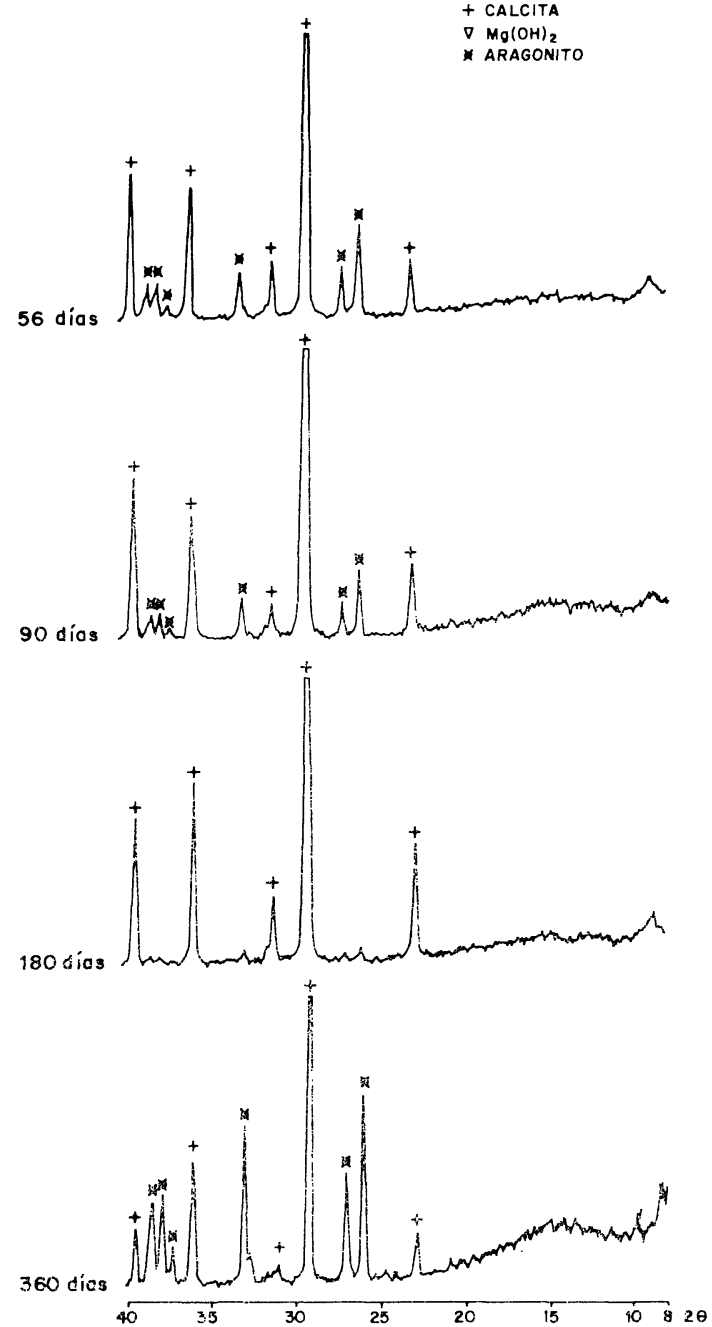

Fig. 4.3.-Sistema: cemento 2/escoria-agua de mar artificial

Mezcla: cemento 2/escoria $=65 / 35$ (en peso). DRX de la nueva fase sólida.

Fig. 4.3.-Sustème: ciment 2/laîier-eau de mer artificielle.

Mélange: ciment $2 /$ laitier $=65 / 35$ (e.p.)

DRX de la nouvelle phase solide. 
las mezclas cemento $1,2,3$ /escoria $=85 / 15$, en peso, respectivamente. En los medios restantes de conservación-ataque que corresponden a las series de probetas fabricadas con las mezclas cemento 1, 2, $3 /$ escoria $=65 / 35-40 / 60$ y $30 / 70$, en peso, es inferior a 10 y superior a 7,5 , debido a la menor cantidad de $\mathrm{Ca}(\mathrm{OH})_{2}$ puesta en juego, ya que existe menos clínker que en los casos anteriores y que parte de dicho hidróxido ha reaccionado con la escoria para dar los compuestos de calcio correspondientes.

Así, el contenido de $\mathrm{Ca}$ (II) en el agua de mar artificial $\left(1,30 \times 10^{-2}\right.$ moles/litro) ha pasado a ser superior a $3,0 \times 10^{-2}$ moles/litro (3) en los dos primeros casos (mezcias,

cemento/escoria $=100 / 0$ y $85 / 15$, en peso) y a $1,40 \times 10^{-2}$ moles/litro en los casos restantantes (mezclas, cemento/escoria $=$ $=65 / 35-40 / 60$ y $30 / 70$, en peso) .
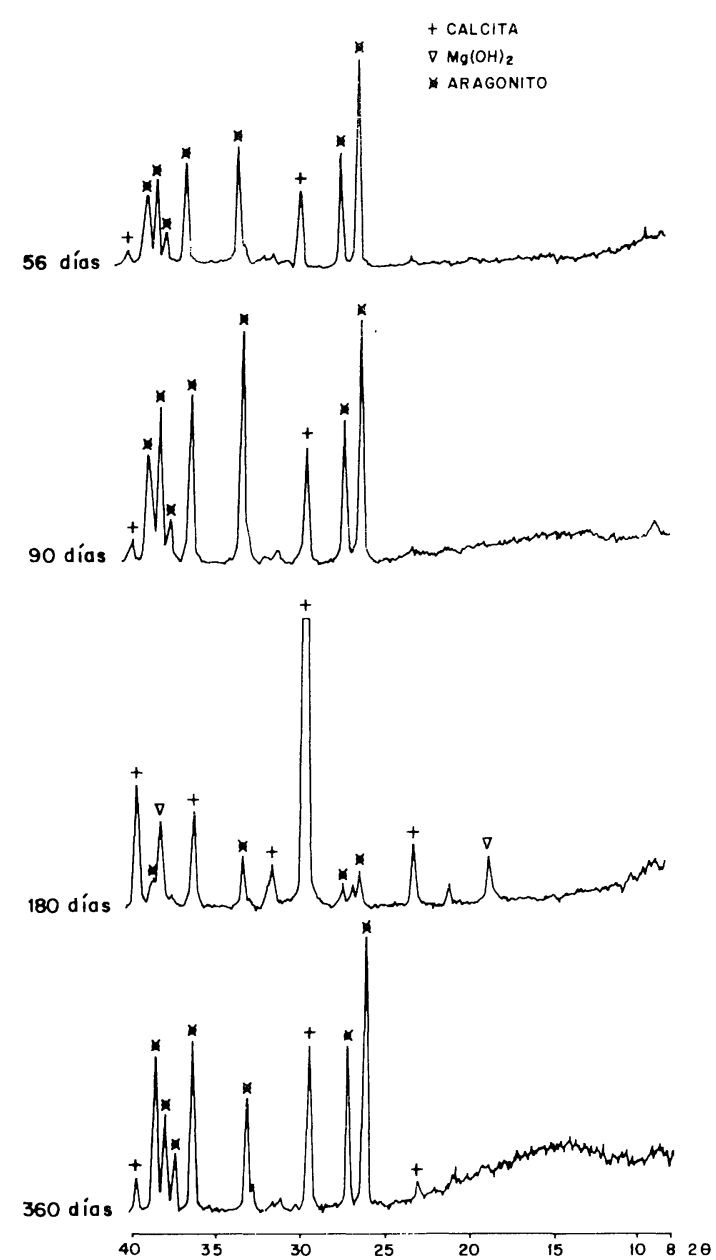

Fig. 4.4.-Sistema: cemento 2/escoria-agua de mar artificial.

Mezcla: cemento 2/escoria $=40 / 60$ (en peso).

DRX de la nueva fase sólida.

Fig. 4.4.-Système: ciment 2/laitier-eau de mer artificielle.

Mélange: ciment $2 /$ laitier $=40 / 60$ (e.p.)

DRX de la nouvelle phase solide. mélanges ciment $(1,2,3) /$ laitier $=85 / 15$, en poids, respectivement, ont été immergées. Dans les solutions de conservation-attaque restantes, qui correspondent aux séries d'éprouvettes fabriquées avec les mélanges ciment 1, 2, $3 /$ laitier $=65 / 35,40 / 60$ et $30 / 70$, en poids, les valeurs sont inférieures à 10 et supérieures à 7,5 , ce qui est dû à une plus petite quantité de $\mathrm{Ca}(\mathrm{OH})_{2}$ mise en jeu, étant donné qu'il y a moins de clinker que dans les cas précédents et qu'une partie de cet hydroxide a fait une réaction avec le laitier pour donner les composants de calcium correspondants.

Ainsi, la teneur de Ca (II) dans l'eau de mer artificielle $\left(1,30 \times 10^{-2}\right.$ moles/litre) est devenu supérieur à $3,0 \times 10^{-2}$ moles/litre (3) dans les deux premiers cas (mélanges, ciment/laitier = $=100 / 0$ et $85 / 15$, en poids) et à $1,40 \times 10^{-2}$ moles/litre dans le reste des cas (mélanges, ciment/laitier $=65 / 35,40 / 60$ et $30 / 70$, en poids).

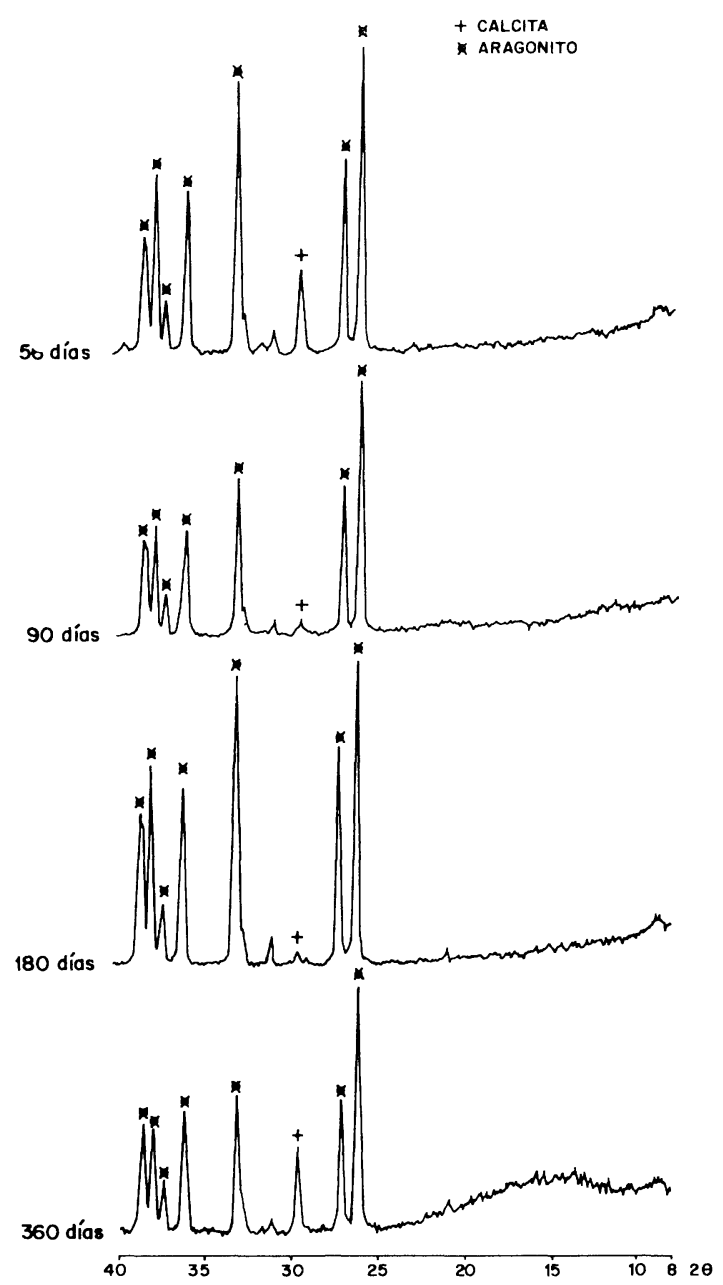

Fig. 4.5.-Sistema: cemento 2/escoria-agua de mar artificial.

Mezcla: cemento 2/escoria $=30 / 70$ (en peso) DRX de la nueva fase sólida.

Fig. 4.5.-Système: ciment 2/laitier-eau de mer artificielle.

Mélange: ciment $2 /$ laitier $=30 / 70$ (e.p.)

$D R X$ de la nouvelle phase solide. 
Por otra parte, el $\mathrm{Mg}$ (II) presente en el agua de mar artificial $\left(5,54 \times 10^{-2}\right.$ moles/litro) ha desaparecido, prácticamente, en los casos estudiados (3) cuyos medios tienen un $\mathrm{pH}>10,5$ - habiendo precipitado como $\mathrm{Mg}(\mathrm{OH})_{2}$ tanto en las probetas como en el agua de mar- dando lugar a la nueva fase sólida junto con la calcita y el aragonito, como se ha probado por DRX (figs. 3.1 y 3.2, $4.1 \mathrm{y}$ $4.2,5.1$ y 5.2$)$.

El Mg (II) precisa un $\mathrm{pH}=10,6$ para que de una disolución $10^{-2} \mathrm{M}$ precipite como $\mathrm{Mg}(\mathrm{OH})_{2}(8)$, dando lugar a la reacción (B):
D'autre part, le Mg (li) présent dans l'eau de mer artificielle $\left(5,54 \times 10^{-2}\right.$ moles/litre) a pratiquement disparu dans les cas étudiés (2) dont les solutions ont un $\mathrm{pH}>10,5$, ayant précipité comme $\mathrm{Mg}(\mathrm{OH})_{2}$ dans les éprouvettes autant que dans l'eau de mer, donnant lieu à une nouvelle phase solide, avec la calcite et l'aragonite, comme il a été prouvé par DRX, (figs. 3.1 et 3.2, 4.1 et $4.2,5.1$ et 5.2).

Le $\mathrm{Mg}(\mathrm{II})$ a besoin d'un $\mathrm{pH}=10,6$ pour qu'une solution $10^{-2} \mathrm{M}$ précipite comme $\mathrm{Mg}(\mathrm{OH})_{2}$ (8), qui donne lieu à la réaction $(\mathrm{B})$ :

$$
\begin{aligned}
& \mathrm{Mg}(\mathrm{II})+2 \mathrm{OH}(\mathrm{I}) \rightleftharpoons \mathrm{Mg}(\mathrm{OH})_{2} \text {. sólido } \\
& \mathrm{Mg}(\mathrm{II})+2 \mathrm{OH}(\mathrm{I}) \rightleftharpoons \mathrm{Mg}(\mathrm{OH})_{2} . \text { solide }
\end{aligned}
$$
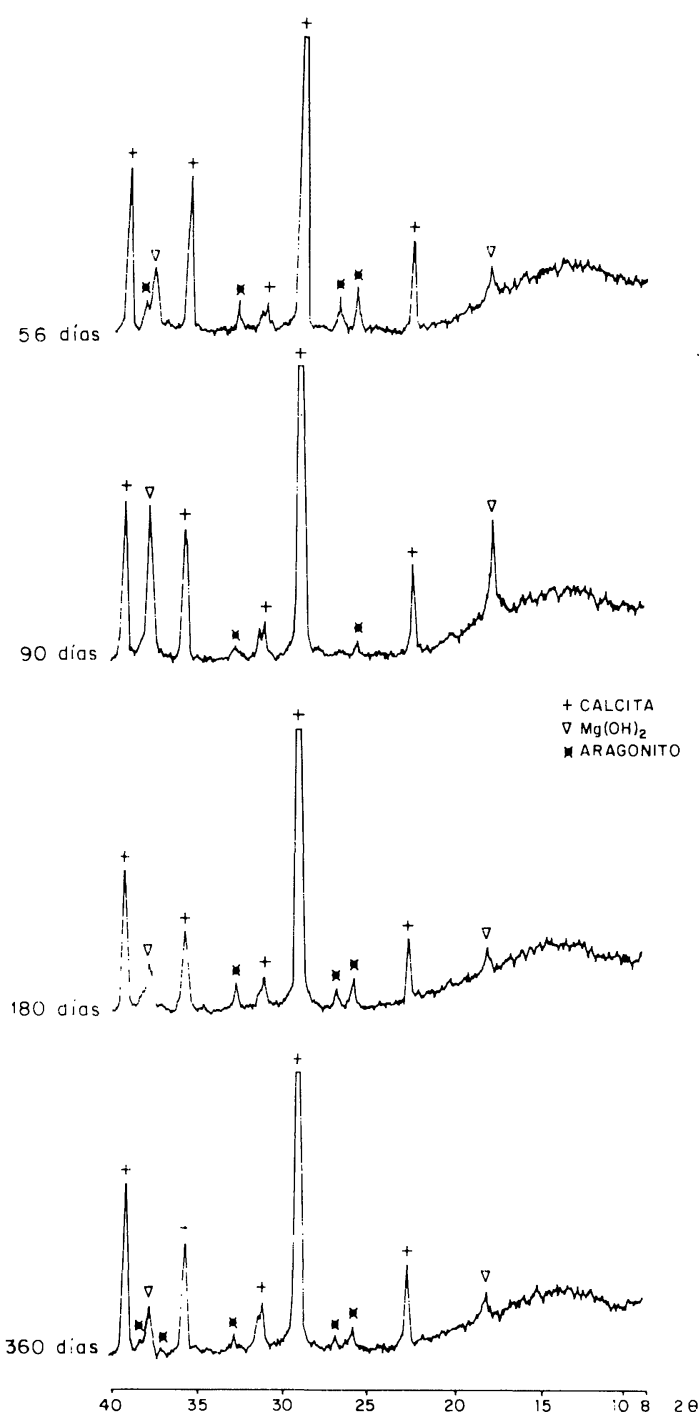

Fig. 5.1.-Sistema: cemento 3/escoria-agua de mar artificial.

Mezcla: cemento $3 /$ escoria $=100 / 0$ (en peso).

DRX de la nueva fase sólida.

Fig. 5.1.-Système: ciment 3/laitier-eau de mer artificielle.

Mélange: ciment $3 /$ laitier $=100 / 0$ (e.p.)

DRX de la nouvelle phase solide.

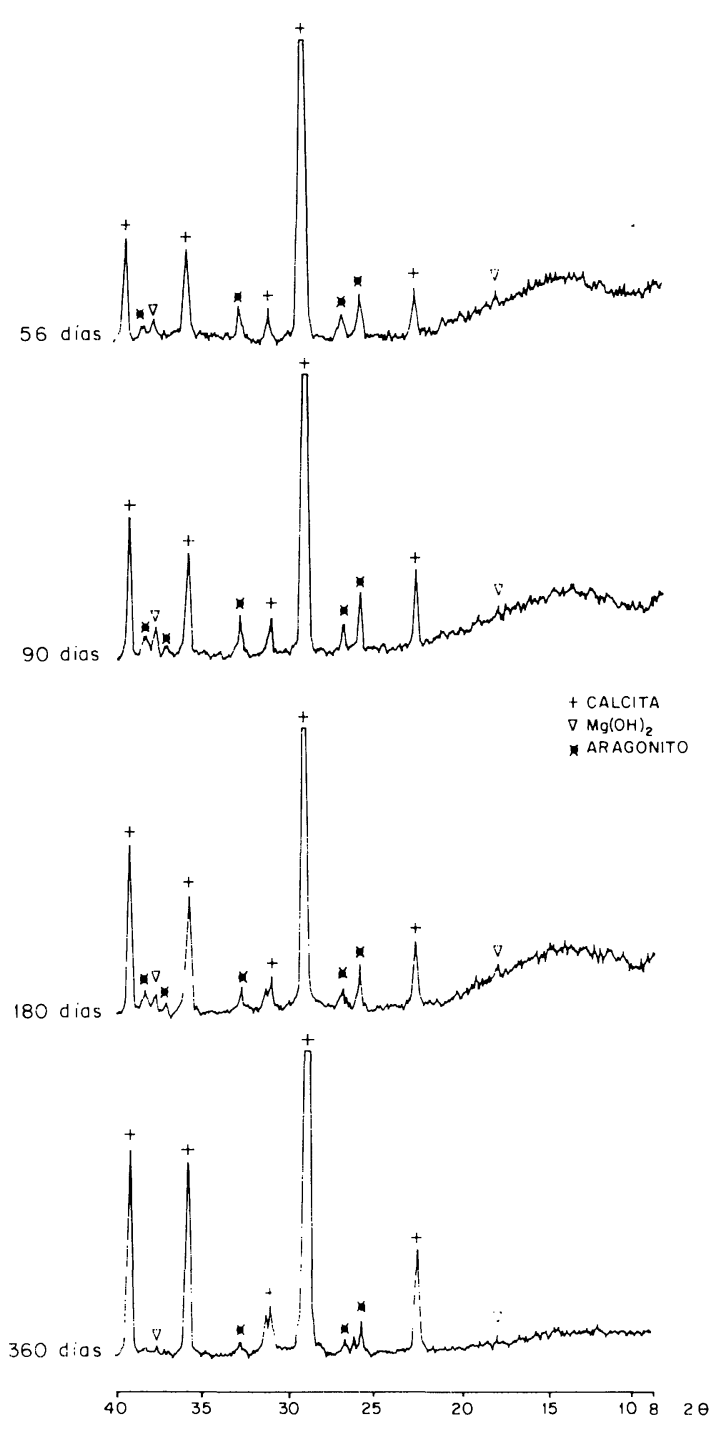

Fig. 5.2.-Sistema: cemento 3/escoria-agua de mar artificial.

Mezcla: cemento $3 /$ escoria $=85 / 15$ (en peso)

DRX de la nueva fase sólida.

Fig. 5.2.-Système: ciment 3/laitier-eau de mer artificielle.

Mélange: ciment $3 /$ laitier $=85 / 15$ (e.p.).

DRX de la nouvelle phase solide. 
por cumplirse $[\mathrm{Mg}(\mathrm{II})][\mathrm{OH}(\mathrm{I})]^{2}>\mathrm{Ps}\left(1,8 \times 10^{-11}\right)$. En estos trabajos se ha probado por DRX que el $\mathrm{Mg}$ (II) ha precipitado como tal $\mathrm{Mg}(\mathrm{OH})_{2}$ en aquellos medios (agua de mar artificial) en donde han estado sumergidas las probetas de mortero hechas con cualquiera de los tres cementos y con sus mezclas con un $15 \%$ de escoria, en donde el $\mathrm{pH}$ es superior a 10,5. Por el contrario, en el agua de mar artificial en donde se han conservado las probetas de mortero fabricadas con las mezclas restantes (cemento 1, 2, 3/escoria $=65 / 35,40 / 60$ y $30 / 70$, en peso) no se ha formado dicho hidróxido por no darse las condiciones adecuadas [de un modo especial, insuficiente concentración de $\mathrm{OH}(\mathrm{I})$ ], quedando parcialmente en la disolución; el resto ha precipitado en las probetas de mortero, en donde se ha detectado como brucita en los DRX correspondientes.
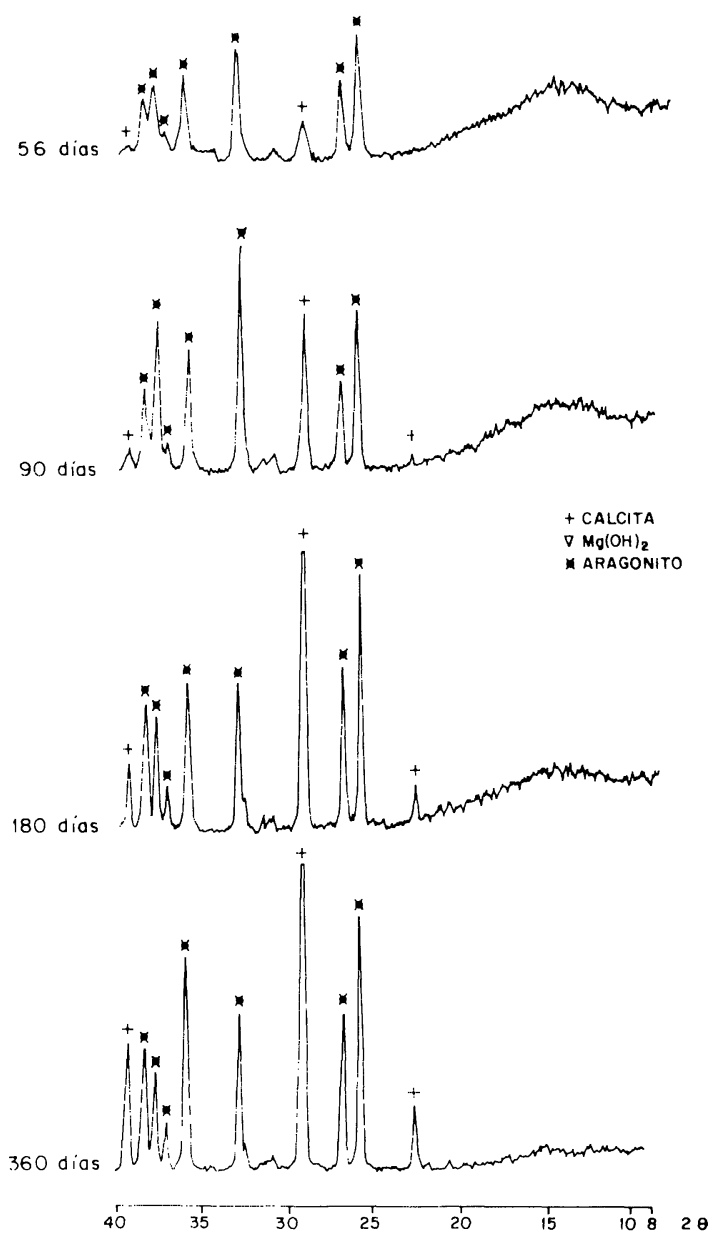

Fig. 5.3.-Sistema: cemento 3/escoria-agua de mar artificial.

Mezcla: cemento 3/escoria $=65 / 35$ (en peso)

DRX de la nueva fase sólida.

Fig. 5.3.-Système: ciment 3/laitier-eau de mer artificielle.

Mélange: ciment $3 /$ laitier $=65 / 35$ (e.p.).

$D R X$ de la nouvelle phase solide. pour avoir lieu $[\mathrm{Mg}(\mathrm{II})][\mathrm{OH}(\mathrm{I})]^{2}>$ Ps $(1,8 \times$ $\left.\times 10^{-11}\right)$. Dans ces travaux il a été prouvé par $D R X$ que le $\mathrm{Mg}(\mathrm{II})$ a précipité comme tel $\mathrm{Mg}(\mathrm{OH})_{2}$ dans les solutions (eau de mer artificielle) où ont été immergées les éprouvettes de mortier faites avec l'un des trois ciments et avec ses mélanges avec $15 \%$ de laitier où le $\mathrm{pH}$ est supérieur à 10,5. Au contraire, dans l'eau de mer artificielle où l'on a conservé les éprouvettes de mortier fabriquées avec les mélanges restants (ciment 1,2 et $3 /$ laitier $=65 / 35,40 / 60$ et $30 / 70$, en poids) l'hydroxide ne s'est pas formé, n'ayant pas les conditions adéquates [spécialement par concentration insuffisante de $\mathrm{OH}(\mathrm{I})]$ qui reste partiellement dans la solution; le reste a été détecté comme brucite dans les DRX correspondants.
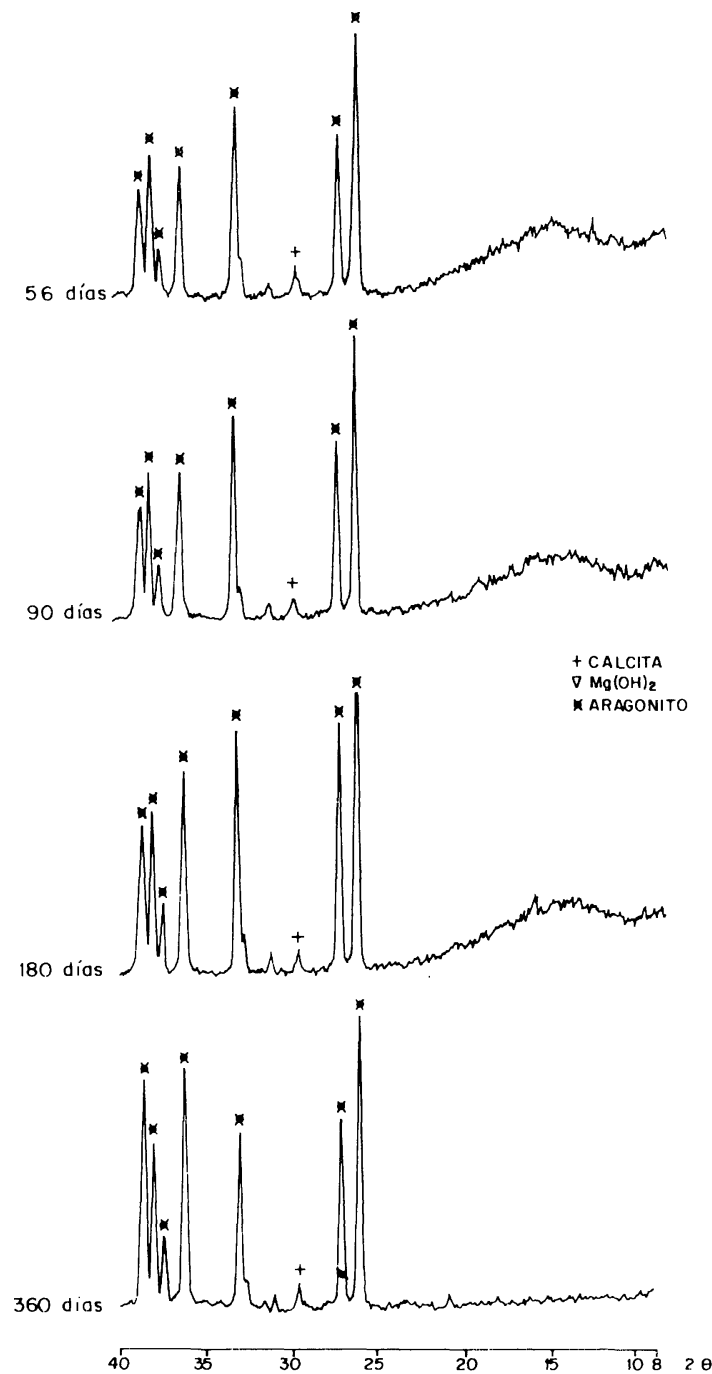

Fig. 5.4.-Sistema: cemento 3/escoria-agua de mar artificial.

Mezcla: cemento $3 /$ escoria $=40 / 60$ (en peso). DRX de la nueva fase sólida.

Fig. 5.4.-Système: ciment 3/laitier-eau de mer artificielle.

Mélange: ciment $3 /$ laitier $=40 / 60$ (e.p.).

DRX de la nouvelle phase solide. 
El $\mathrm{CO}_{2}$ disuelto en el agua de mar artificial es capaz de reaccionar con el $\mathrm{Ca}$ (II), en medio básico, para formar $\mathrm{CaCO}_{3}$.sólido, según (C):
Le $\mathrm{CO}_{2}$ dissout dans l'eau de mer artificielle est capable de réagir avec le $\mathrm{Ca}$ (II) en solution basique pour former du $\mathrm{CaCO}_{3}$ solide, d'après (C):

$$
\begin{aligned}
& \mathrm{CO}_{2}+\mathrm{Ca}(\mathrm{II})+2 \mathrm{OH}(\mathrm{I}) \rightleftharpoons \mathrm{CaCO}_{3} \text {. sólido }+\mathrm{H}_{2} \mathrm{O} \\
& \mathrm{CO}_{2}+\mathrm{Ca}(\mathrm{II})+2 \mathrm{OH}(\mathrm{I}) \rightleftharpoons \mathrm{CaCO}_{3} \text {.solide }+\mathrm{H}_{2} \mathrm{O}
\end{aligned}
$$

siempre que se cumpla $\left[\mathrm{CO}_{3}(\mathrm{II})\right][\mathrm{Ca}(\mathrm{II})]>$ $>$ P's $\left(4,8 \times 10^{-9}\right)$; a la vez se produce una disminución de la concentración de iones $\mathrm{OH}$ (I) y, por consiguiente, del valor del $\mathrm{pH}$.
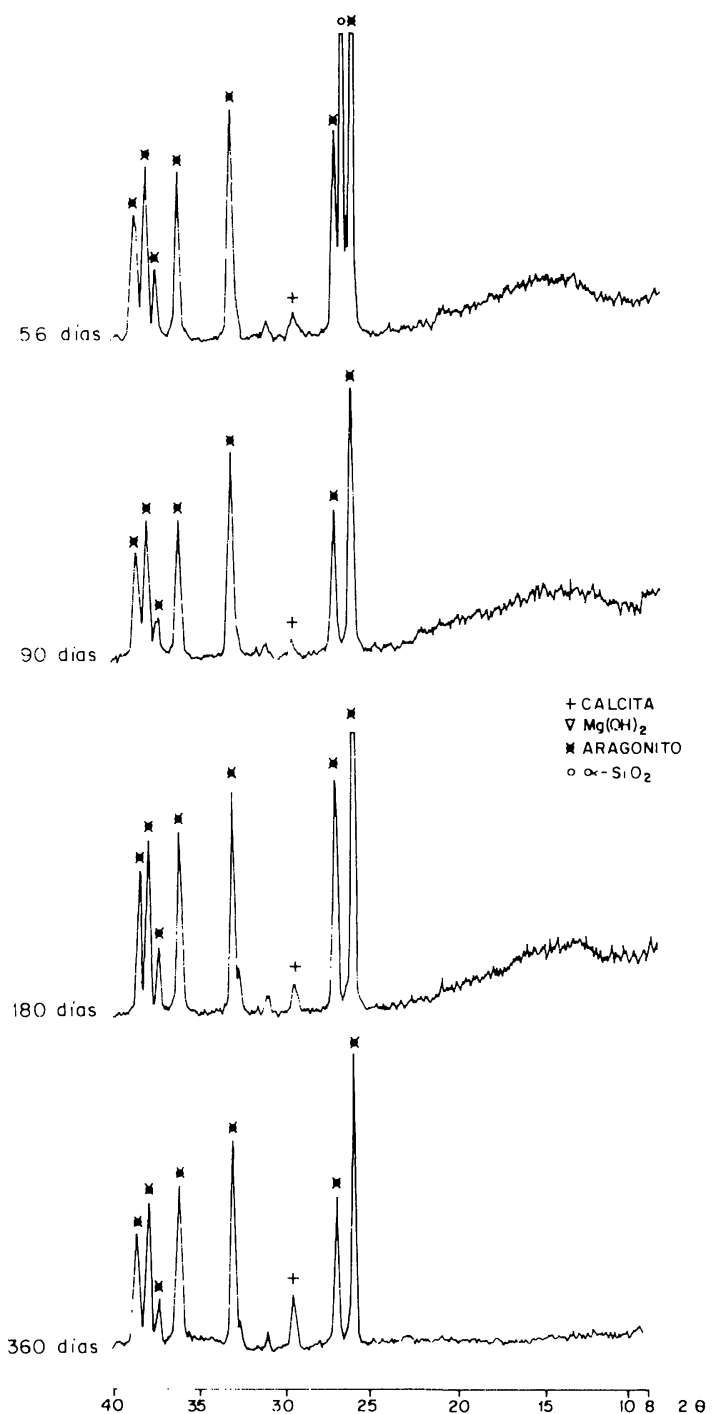

Fig. 5.5.-Sistema: cemento 3/escoria-agua de mar artificial.

Mezcla: cemento $3 /$ escoria $=30 / 70$ (en peso)

DRX de la nueva fase sólida.

Fig. 5.5.-Système: ciment 3/laitier-eau de mer artificielle.

Mélange: ciment $3 /$ laitier $=30 / 70$ (e.p.).

DRX de la nouvelle phase solide. si toujours il y a $\left[\mathrm{CO}_{3}(\mathrm{II})\right]$ [Ca (II)] $>$ P's $(4,8 \times$ $\left.\times 10^{-9}\right)$; en même temps se produit une diminution de concentration d'ions $\mathrm{OH}(I)$ et, par conséquent, une diminution de la valeur du $\mathrm{pH}$.

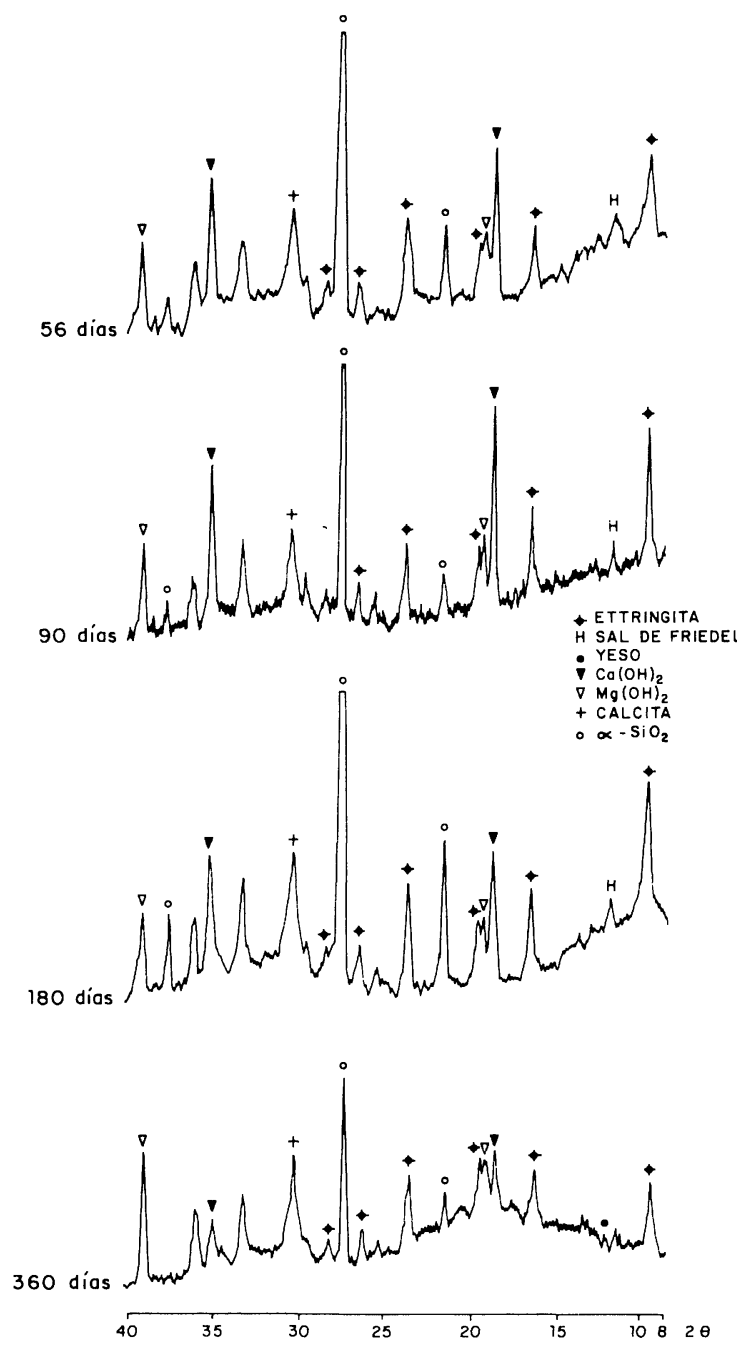

Fig. 6.1.-Sistema: cemento 1/escoria-agua de mar artificial.

Mezcla: cemento $1 /$ escoria $=100 / 0$ (en peso). DRX de la fracción enriquecida.

Fig. 6.1.-Système: ciment 1/laitier-eau de mer artificielle.

Mélange: ciment $1 /$ laitier $=100 / 0$ (e.p.)

DRX, fraction enrichie (pâte ciment).

MATERIALES DE COSTRUCCION, Vol. 37, n.0207, julio/agosto/septiembre 1987 
La disminución de iones $\mathrm{OH}(\mathrm{I})$, equilibrios (B) (C), y del Ca (II), equilibrio (C), del agua de mar artificial favorece la reacción $(A)$,

- disolución del $\mathrm{Ca}(\mathrm{OH})_{2}$ - y por consiguiente el avance de las reacciones de hidratación de los compuestos del clínker, por lo que se libera más protlandita que pasa, en parte, al medio en forma iónica; a la vez, los silicatos de calcio se degradan.

El precipitado de $\mathrm{CaCO}_{3}$ ha cristalizado como calcita y como aragonito, como se ha probado por DRX (figs. 3.1 a 3.5, 4.1 a 4.5 y 5.1 a 5.5 ), en proporciones diversas, predominando una sobre otra según las condiciones del sistema $y$, de un modo especial, de la mezcla utilizada (cemento/escoria) en la fabricación de las probetas de mortero que, a su vez, influye en
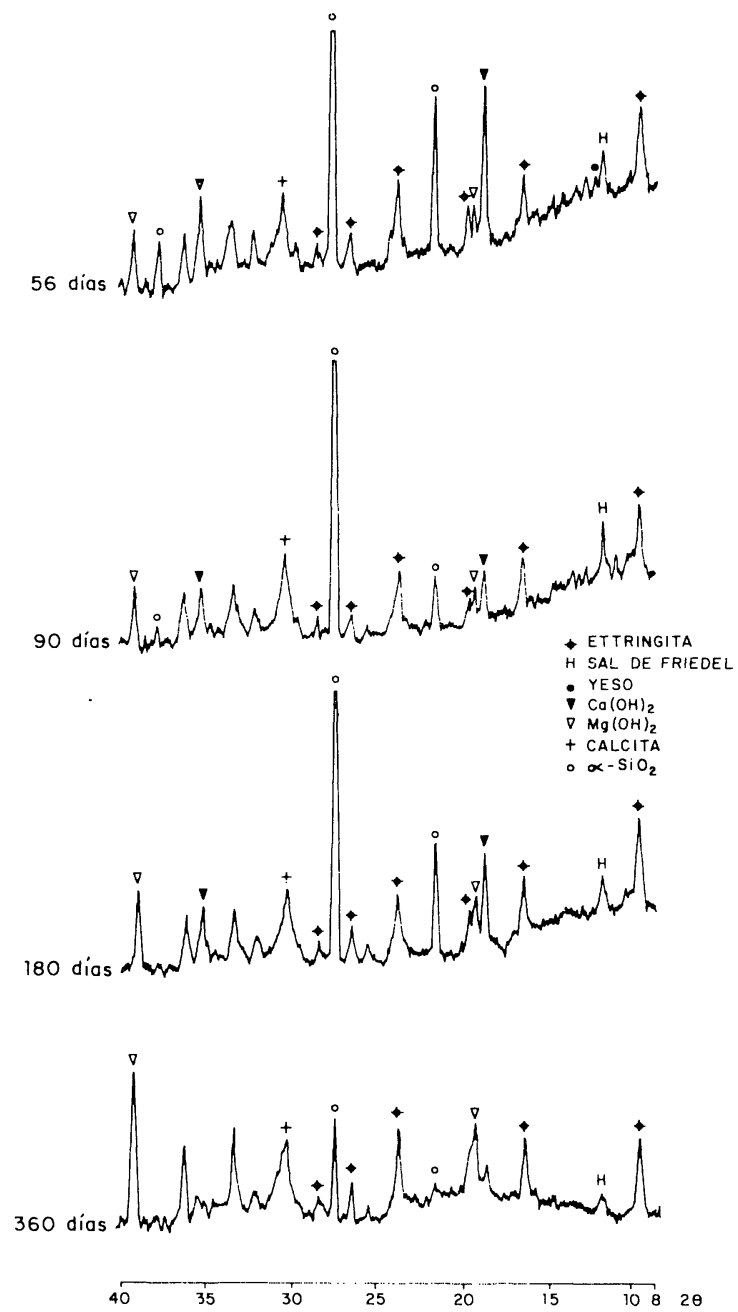

Fig. 6.2.-Sistema: cemento 1/escoria-agua de mar artificial.

Mezcla: cemento $1 /$ escoria $=85 / 15$ (en peso).

DRX de la fracción enriquecida.

Fig. 6.2.-Système: ciment 1/laitier-eau de mer artificielle.

Mélange: ciment 1/laitier $=85 / 15$ (e.p.).

DRX, fraction enrichie (pâte ciment).
La diminution d'ions $\mathrm{OH}(\mathrm{I})$, équilibres $(B)(C)$, et celui du Ca (II), équilibre (C), de l'eau de mer artificielle favorise la réaction $(A)$-dissolution du $\mathrm{Ca}(\mathrm{OH})_{2}$ - et par conséquent la progression des réactions d'hydratation des composants du clinker, raison pour laquelle une plus grande quantité de portlandite est libérée, et passe en partie, à la solution sous forme ionique; en même temps, les silicates de calcium se dégradent.

Le précipité de $\mathrm{CaCO}_{3}$ a cristallisé comme calcite et comme aragonite, comme il a été prouvé par DRX (figs. 3.1 à $3.5,4.1$ à 4.5 et 5.1 à 5.5), dans des proportions différentes, avec prédominance de l'une sur l'autre selon les conditions du système et d'une façon toute spéciale, du mélange employé (ciment/laitier) dans la fabrication des éprouvettes de mortier
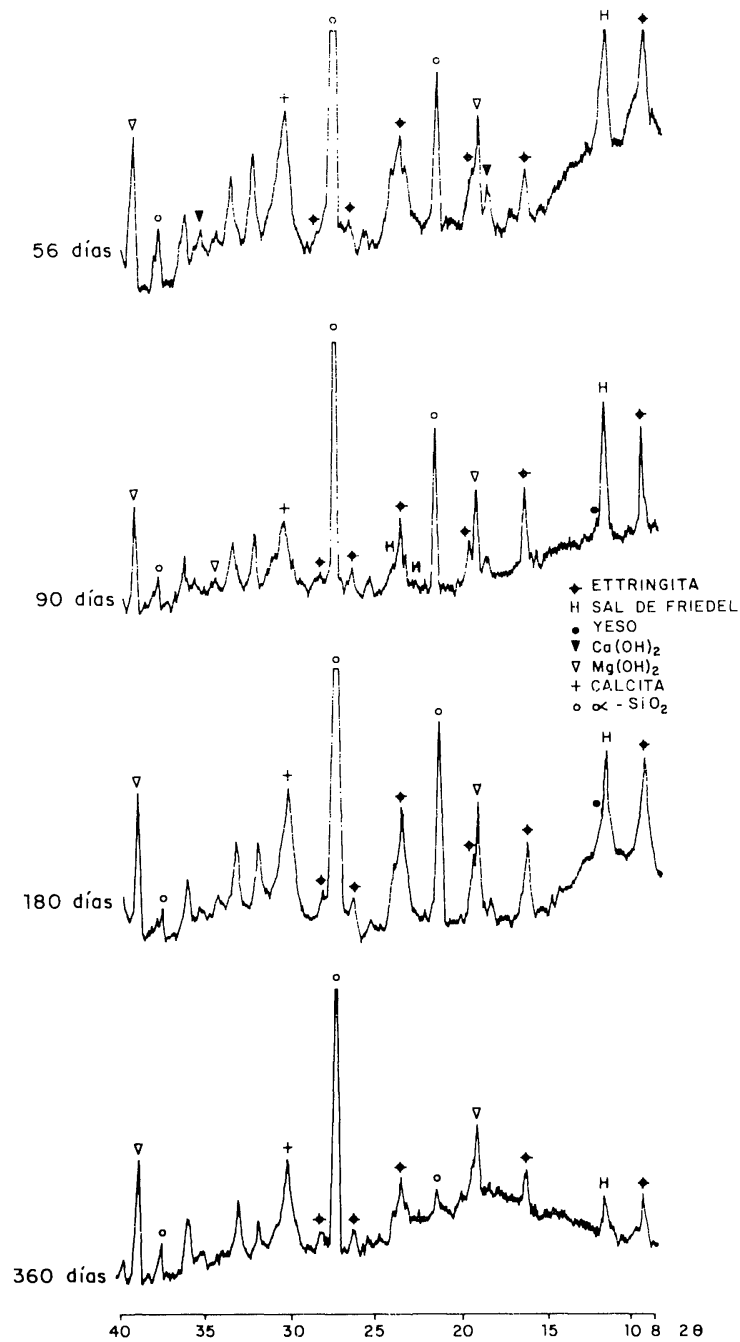

Fig. 6.3.-Sistema: cemento 1/escoria-agua de mar artificial.

Mezcla: cemento 1/escoria $=65 / 35$ (en peso).

DRX de la fracción enriquecida.

Fig. 6.3.-Système: ciment 1/laitier-eau de mer artificielle.

Mélange: ciment 1/laitier $=65 / 35$ (e.p.).

$D R X$, fraction enrichie (pâte ciment). 
las características del agua de mar artificial en donde han estado sumergidas $(\mathrm{pH}$, concentración iónica, formación de una nueva fase sólida, etc.). En este trabajo se ha probado que:

a. la calcita predomina sobre el aragonito en aquellos casos en los que las condiciones finales del medio (agua de mar artificial), en donde han estado sumergidas las probetas de mortero, son:

$\mathrm{pH}>10,5$ (el original es 6,5); [Ca (II)] > $>3 \times 10^{-2} ;[\mathrm{Mg}(\mathrm{II})]$ nula $0<0,5 \times 10^{-2}$; formación de una nueva fase sólida en donde existen los compuestos cristalinos aragonito (en pequeña cantidad), calcita y brucita, como sucede en los medios correspondientes a las series de probetas hechas con los distintos cementos
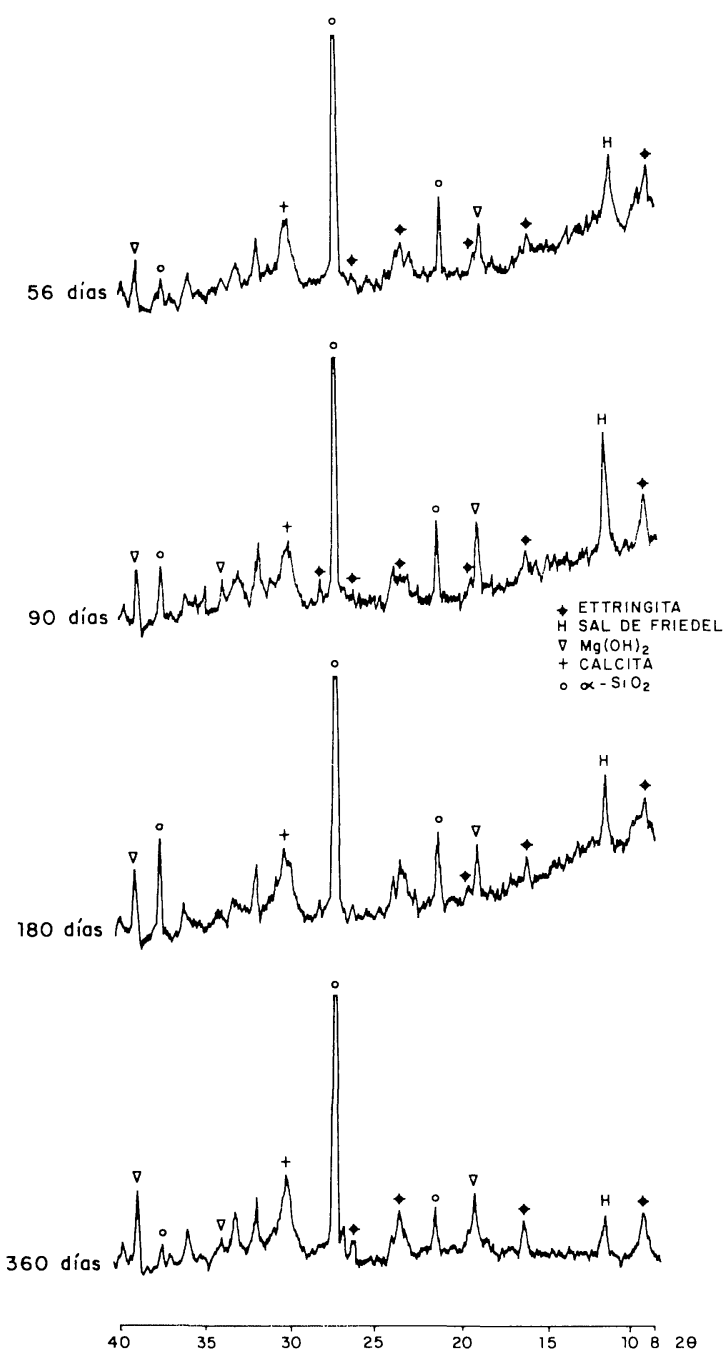

Fig. 6.4.-Sistema: cemento 1/escoria-agua de mar artificial.

Mezcla: cemento $1 /$ escoria $=40 / 60$ (en peso).

DRX de la fracción enriquecida.

Fig. 6.4.-Système: ciment 1/laitier-eau de mer artificielle.

Mélange: ciment $1 /$ laitier $=40 / 60$ (e.p.)

$D R X$, fraction enrichie (pâte ciment) qui, à son tour, a une influence sur les caractéristiques de l'eau de mer artificielle où elles ont été immergées ( $\mathrm{HH}$, concentration ionique, formation d'une nouvelle phase solide, etc.). Dans ce travail il a été prouvé que:

a. la calcite l'emporte sur l'aragonite, dans les cas où les conditions finales de la solution (eau de mer artificielle), où les éprouvettes ont été immergées, sont: $\mathrm{pH}>10,5$ (à l'origine 6,5); [Ca (II)] > $3 \times 10^{-2}$; [Mg (II)] nul ou $<0,5 \times 10^{-2}$; formation d'une nouvelle phase solide où se trouvent les composants cristallins aragonite (en petite quantité), calcite et brucite, comme il arrive dans les solutions qui correspondent aux séries d'éprouvettes fabriquées avec les différents ciments étudiés et avec les mélanges qui ont $15 \%$ de laitier (en poids)

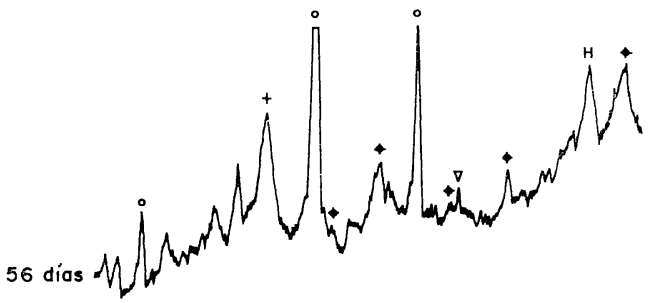

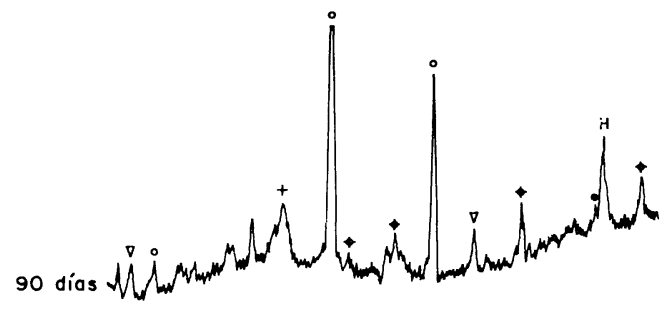

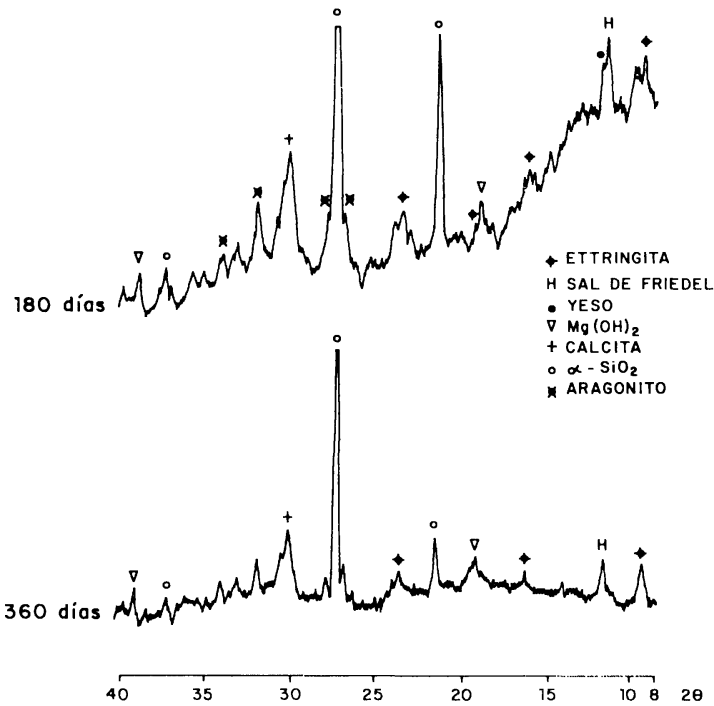

Fig. 6.5.-Sistema: cemento 1/escoria-agua de mar artificial.

Mezcla: cemento $1 /$ escoria $=30 / 70$ (en peso)

DRX de la fracción enriquecida.

Fig. 6.5.-Système: ciment 1/laitier-eau de mer artificielle.

Mélange: ciment $1 /$ laitier $=30 / 70$ (e.p.).

DRX, fraction enrichie (pâte ciment). 
estudiados y con las mezclas que tienen $15 \%$ de escoria (en peso) y -además, a veces- en la mezcla cemento/escoria $=$ $=65 / 35$, en peso,

b. el aragonito predomina sobre la calcita en aquellos casos cuyas características del agua de mar, en donde han estado sumergidas las probetas de mortero, son: $\mathrm{pH}<8,5$ y $>7,5$; [Ca (II)] $<2,8 \times 10^{-2}$ y $>1,3 \times 10^{-2} ;[\mathrm{Mg}(\mathrm{II})]<3,6 \times 10^{-2}$ y $>1,1 \times 10^{-2}$; formación de una nueva fase sólida en donde se encuentran los compuestos cristalinos calcita (en pequeña cantidad) y aragonito, como sucede en los medios en donde se han conservado las probetas de mortero hechas con las mezclas cemento/escoria $=40 / 60$ y $30 / 70$, en peso,

c. para los medios en donde han estado las series de probetas elaboradas con las
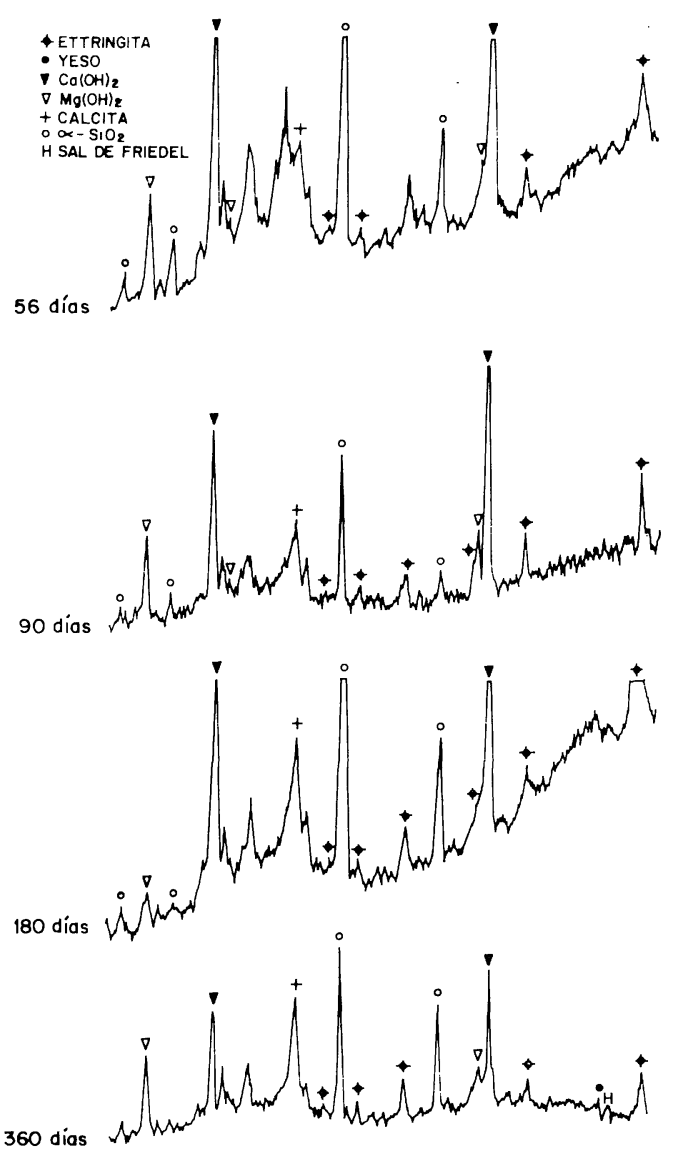

$$
\begin{array}{llllllll}
40 & 35 & 30 & 25 & 20 & 15 & 10 & 8
\end{array}
$$

Fig. 7.1.-Sistema: cemento 2/escoria-agua de mar artificial.

Mezcla: cemento 2 /escoria $=100 / 0$ (en peso).

DRX de la fracción enriquecida.

Fig. 7.1.-Système: ciment 2/laitier-eau de mer artificielle.

Mélange: ciment $2 /$ laitier $=100 / 0$ (e.p.)

$D R X$, fraction enrichie (pâte ciment), et -aussi, quelquefois-dans les mélanges ciment/laitier $=65 / 35$, en poids;

b. l'aragonite a prédominance sur la calcite dans les cas où les caractéristiques de l'eau de mer, où les éprouvettes de mortier ont été immergées, sont: $\mathrm{pH}<8,5$ et $>7,5$; $[\mathrm{Ca}(I I)]<2,8 \times 10^{-2}$ et $>1,3 \times 10^{-2}$; $[\mathrm{Mg}(\mathrm{II})]<3,6 \times 10^{-2}$ et $>1,1 \times 10^{-2}$; formation d'une nouvelle phase solide où se trouvent les composants cristallins calcite (en petite quantité) et aragonite, comme il arrive dans les solutions où l'on a conservé les éprouvettes de mortier fabriquées avec les mélanges ciment/laitier $=40 / 60$ et $30 / 70$, en poids;

c. pour les solutions où ont été immergées les séries d'éprouvettes fabriquées avec les
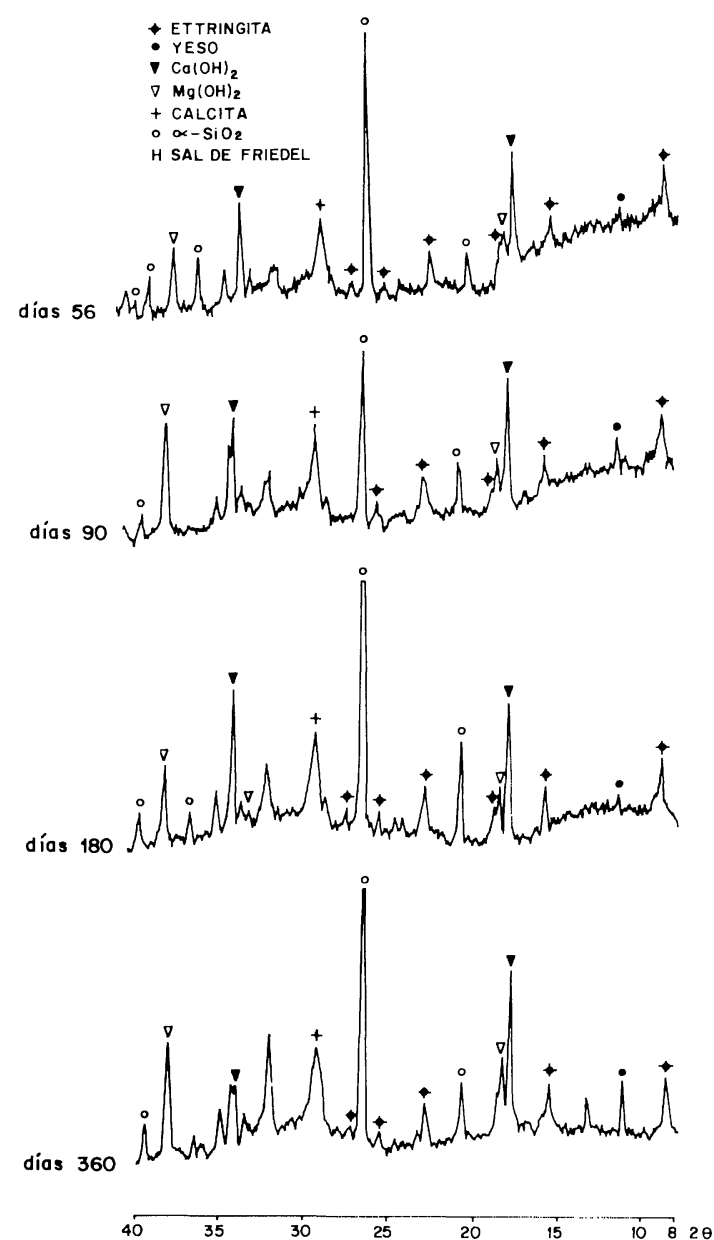

Fig. 7.2.-Sistema: cemento 2/escoria-agua de mar artificial.

Mezcla: cemento 2/escoria $=85 / 15$ (en peso)

DRX de la fracción enriquecida.

Fig. 7.2.-Système: ciment 2/laitier-eau de mer artificielle.

Mélange: ciment 2/laitier $=85 / 15$ (e.p.)

$D R X$, fraction enrichie (pâte ciment). 
mezclas cemento $(1$ y 3 )/escoria $=65 / 35$, en peso, cuyas características son: $\mathrm{pH}<10$ y $>7,3 ;$ [Ca (II)] $<3,5 \times 10^{-2}$ y $>2,8 \times 10^{-2} ;[\mathrm{Mg}(\mathrm{II})] \simeq 0,1 \times 10^{-2}$, las cantidades de calcita y de aragonito son, a veces, del mismo orden.

En resumen, la presencia de $\mathrm{Mg}$ (II) en la disolución (agua de mar artificial), que es función del $\mathrm{pH}$, tiene una influencia extraordinaria en la formación de calcita y aragonito, así como las cantidades relativas de $\mathrm{Ca}$ (II) y de $\mathrm{Mg}$ (II).

\subsection{Estudio de la fracción enriquecida (pasta de cemento)}

En la fracción enriquecida (pasta de cemento)
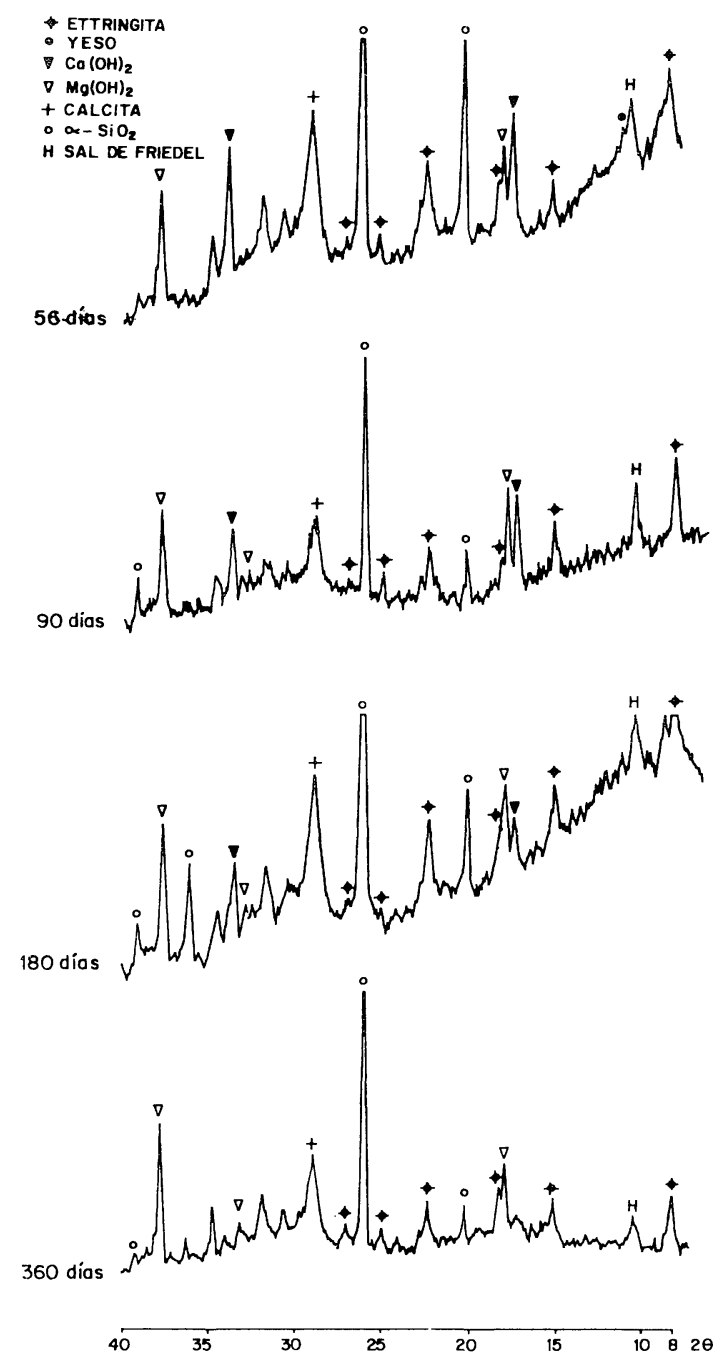

Fig. 7.3.- Sistema: cemento 2/escoria-agua de mar artificial.

Mezcla: cemento 2/escoria $=65 / 35$ (en peso).

DRX de la fracción enriquecida.

Fig. 7.3.-Système: ciment 2/laitier-eau de mer artificielle.

Mélange: ciment $2 /$ laitier $=65 / 35$ (e.p.).

$D R X$, fraction enrichie (pâte ciment) melanges ciment $(1$ et 3 )/laitier $=65 / 35$, en poids, dont les caractéristiques sont: $\mathrm{pH}<10$ et $>7,3$; $[\mathrm{Ca}(\mathrm{II})]<3,5 \times 10^{-2}$ et $>2,8 \times 10^{-2} ;[\mathrm{Mg}(\mathrm{II})] \simeq 0,1 \times 10^{-2}$, les quantités de calcite et d'aragonite sont, quelquefois, du même ordre.

En résumé, la présence de $M g$ (II) dans la solution (eau de mer artificielle) qui est fonction $\mathrm{du} \mathrm{pH}$, a une extraordinaire influence sur la formation de la calcite et de l'aragonite, ainsi que les quantités relatives de $\mathrm{Ca}$ (II) et de Mg (II).

\subsection{Etude de la fraction enrichie (pâte de ciment)}

Dans la fraction enrichie (pâte de ciment)

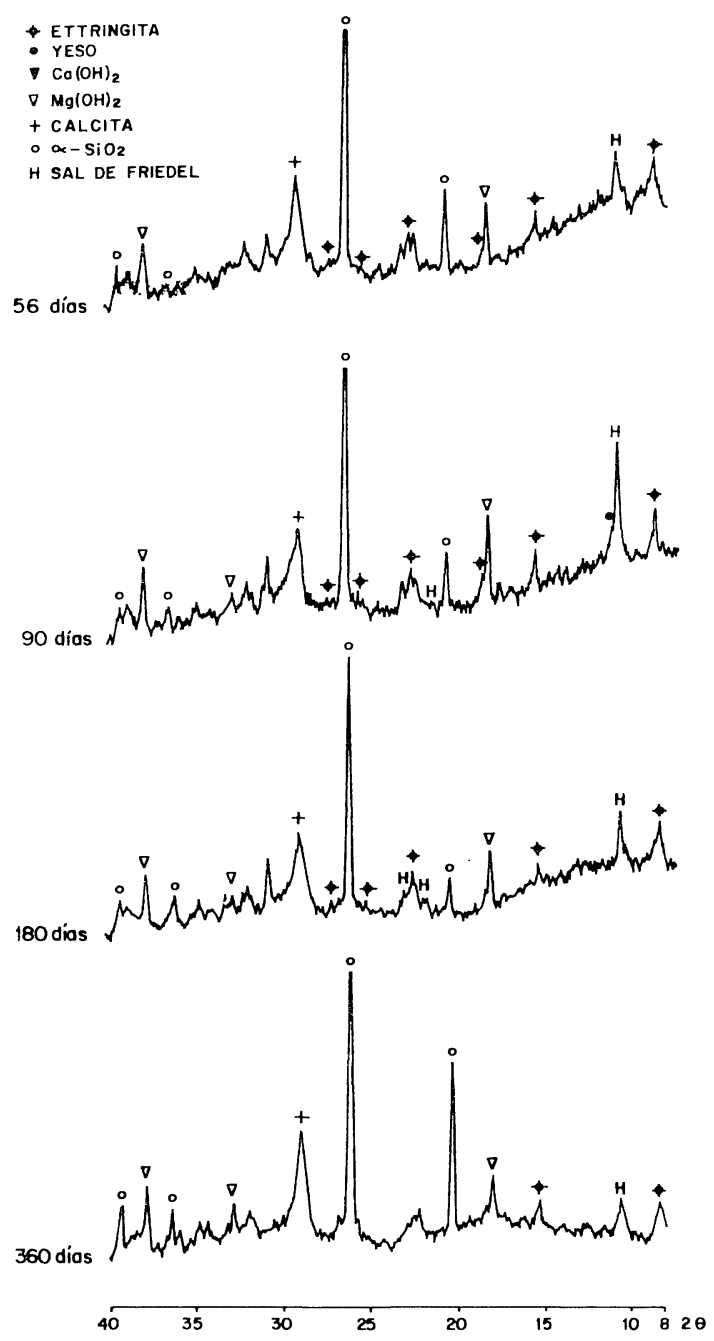

Fig. 7.4.-Sistema: cemento 2/escoria-agua de mar artificial.

Mezcla: cemento 2 /escoria $=40 / 60$ (en peso).

DRX de la fracción enriquecida.

Fig. 7.4.-Système: ciment 2/laitier-eau de mer artificielle.

Mélange: ciment $2 /$ laitier $=40 / 60$ (e.p.)

$D R X$, fraction enrichie (pâte ciment).

MATERIALES DE COSTRUCCION, Vol. 37, n. 207, julio/agosto/septiembre 1987 
extraída de una de las probetas de mortero de cada serie, hechas con los cementos $1-2$ y 3 y con las mezclas cemento/escoria $=85 / 15$ $65 / 35$ - $40 / 60$ y $30 / 70$, en peso, se han identificado por difracción de rayos $X$ los picos de los compuestos cristalinos ettringita, sal de Friedel, yeso, portlandita, brucita y calcita, además de $\alpha-\mathrm{SiO}_{2}$ que procede de la arena utilizada en la fabricación de dichas probetas (figs. 6.1 a $6.5,7.1$ a 7,5 y 8.1 a 8.5 ), en donde se observa la influencia que ejerce la adición de escoria, y el tiempo de conservación-ataque de las probetas, en la formación o eliminación de los compuestos mencionados.

La intensidad de los picos de la ettringita, $3 \mathrm{CaO} . \mathrm{Al}_{2} \mathrm{O}_{3} .3 \mathrm{CaSO}_{4} .31 \mathrm{H}_{2} \mathrm{O}$, es mayor que en los DRX correspondientes a las muestras extraite de l'une des éprouvettes de mortier de chaque série, fabriquées avec les ciments 1,2 et 3 et avec les mélanges cimet/laitier $=85 / 15$, $65 / 35,40 / 60$ et $30 / 70$, en poids, on a identifié par diffraction de rayons $X$, les pics des composants cristallins ettringite, sel de Friedel, gypse, portlandite, brucite et calcite, en plus de $\alpha-\mathrm{SiO}_{2}$ qui procède du sable utilisé dans la fabrication de ces éprouvettes (figs. 6.1 à 6.5 , 7.1 à 7.5 et 8.1 à 8.5 ), où l'on observe l'influence exercée par l'addition de laitier et par le temps de conservation-attaque des éprouvettes, dans la formation ou l'élimination des composants mentionnés.

L'intensité des pics d'ettringite, $3 \mathrm{CaO} \cdot \mathrm{Al}_{2} \mathrm{O}_{3}$ . $3 \mathrm{CaSO}_{4} .31 \mathrm{H}_{2} \mathrm{O}$, est plus grande que dans les DRX correspondant aux échantillons extraits
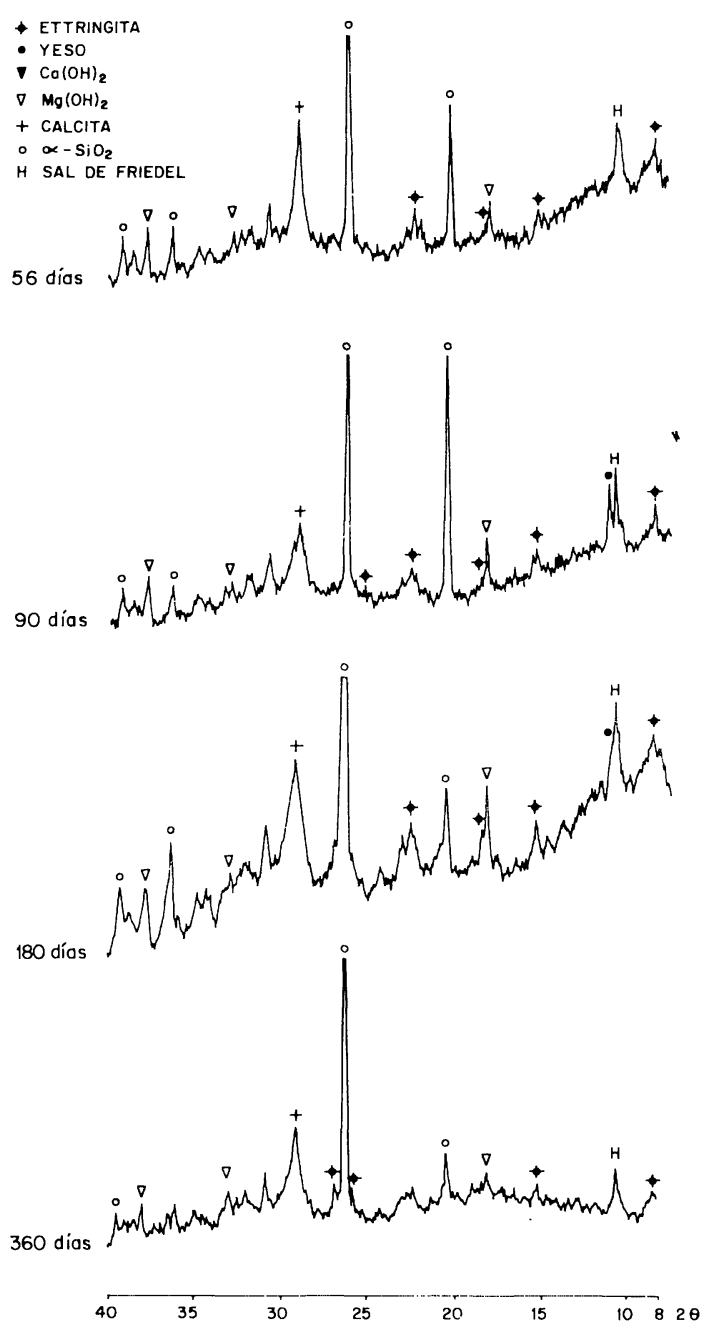

Fig. 7.5.-Sistema: cemento 2/escoria-agua de mar artificial.

Mezcla: cemento 2/escoria $=30 / 70$ (en peso).

DRX de la fracción enriquecida.

Fig. 7.5.-Système: ciment 2/laitier-eau de mer artificielle.

Mélange: ciment $2 /$ laitier $=30 / 70$ (e.p.)

DRX, fraction enrichie (pâte ciment).

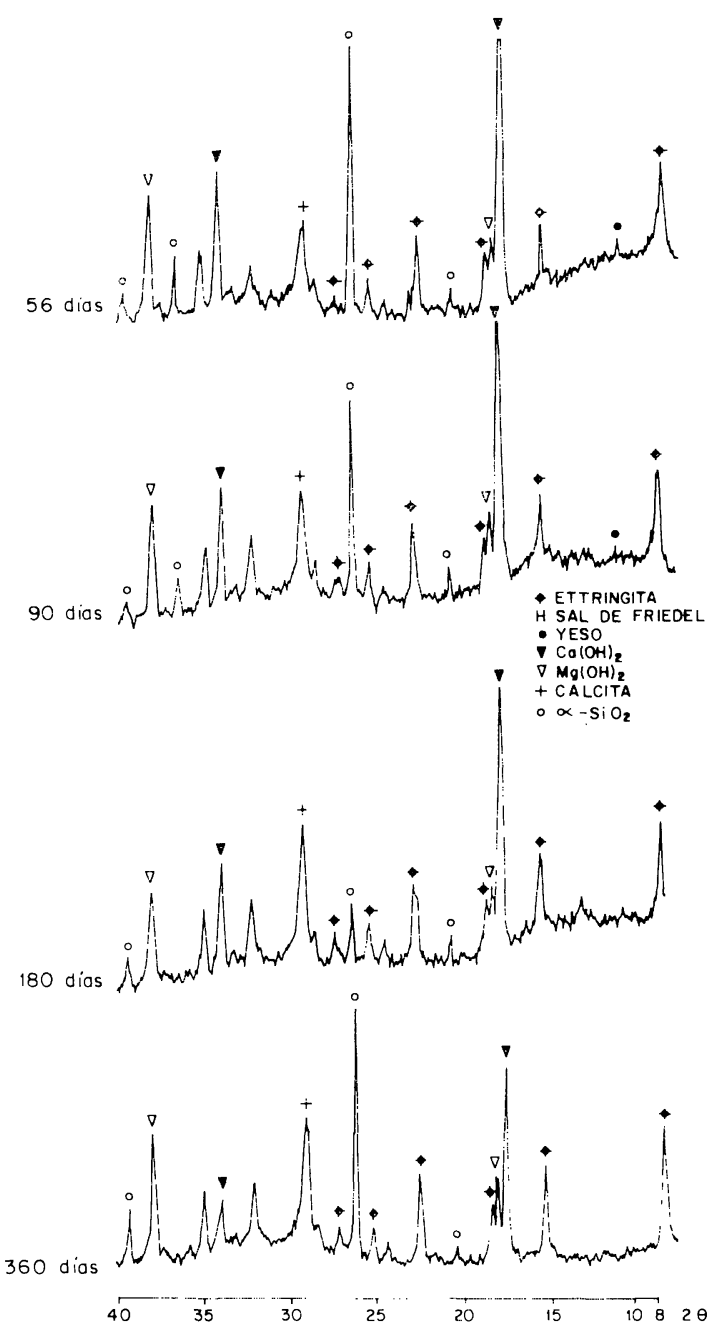

Fig. 8.1.-Sistema: cemento 3/escoria-agua de mar artificial.

Mezcla: cemento $3 /$ escoria $=100 / 0$ (en peso).

DRX de la fracción enriquecida.

Fig. 7.1.-Système: ciment 3/laitier-eau de mer artificielle.

Mélange: ciment $3 /$ laitier $=100 / 0$ (e.p.)

DRX, fraction enrichie (pâte ciment). 
extraídas de probetas de las series análogas sumergidas en agua potable filtrada. Este incremento se debe a la mayor cantidad de etrringita que se ha formado, de un modo especial, por reacción de los iones $\mathrm{SO}_{4}$ (II) que existen en el agua de mar artificial con los iones $\mathrm{Ca}$ (II) del $\mathrm{Ca}(\mathrm{OH})_{2}$ presente en la interfase de las probetas de mortero $\left[\mathrm{Ca}(\mathrm{OH})_{2}\right.$.sólido $\rightleftharpoons \mathrm{Ca}(\mathrm{OH})_{2}$.disuelto], produciendo yeso secundario, y éste con el aluminato de calcio hidratado del cemento, por una parte, y porque, además, la escoria que se ha adicionado al cemento da lugar a la formación de ettringita por reacción del aluminato de calcio hidratado, procedente de la reacción de la gehelenita de la escoria con el $\mathrm{Ca}(\mathrm{OH})_{2}$ de la fracción hidratada del clínker - según (D)-.

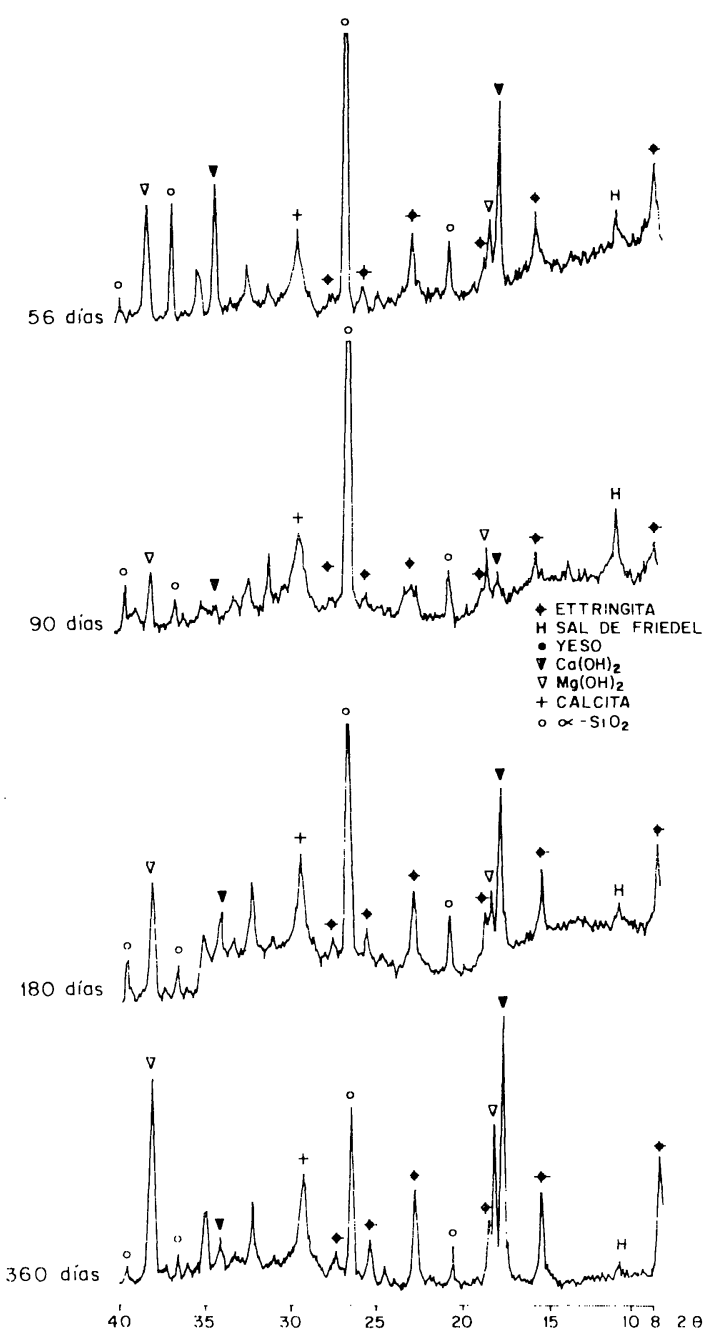

Fig. 8.2.-Sistema: cemento 3/escoria-agua de mar artificial.

Mezcla: cemento $3 /$ escoria $=85 / 15$ (en peso).

DRX de la fracción enriquecida.

Fig. 8.2.-Système: ciment 3/laitier-eau de mer artificielle.

Mélange: ciment $3 /$ laitier $=85 / 15$ (e.p.).

DRX, fraction enrichie (pâte ciment) des éprouvettes des séries analogues immergées dans l'eau douce. Cette augmentation est dûe à une quantité plus grande d'ettringite qui s'est formée, d'une façon toute spéciale, par réaction des ions $\mathrm{SO}_{4}$ (II) qui existent dans l'eau de mer artificielle avec des ions $\mathrm{Ca}$ (II) du $\mathrm{Ca}(\mathrm{OH})_{2}$ présent dans l'interphase des éprouvettes de mortier $\left[\mathrm{Ca}(\mathrm{OH})_{2}\right.$ solide $\rightleftharpoons \mathrm{Ca}(\mathrm{OH})_{2}$ dissout], produisant gypse secondaire, et celui-là, avec l'aluminate de calcium hydraté du ciment, d'une part, et parcequ'en plus le laitier ajouté au ciment donne lieu à la formation d'ettringite par réaction de l'aluminate de calcium hydraté procédant de la réaction de la géhélénite du laitier avec le $\mathrm{Ca}(\mathrm{OH})_{2}$ de la fraction hydratée du clinker -d'après $(D)$ -

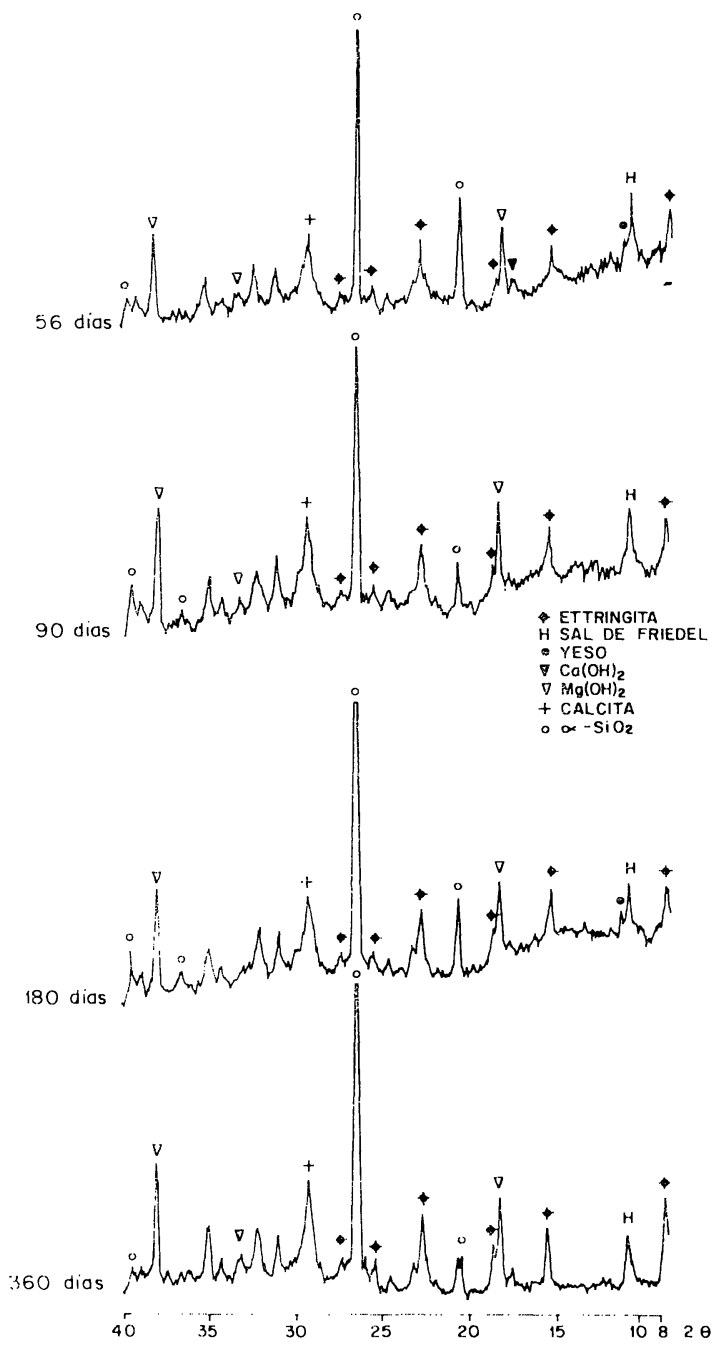

Fig. 8.3.-Sistema: cemento 3/escoria-agua de mar artificial.

Mezcla: cemento $3 /$ escoria $=65 / 35$ (en peso).

DRX de la fracción enriquecida.

Fig. 8.3.-Système: ciment 3/laitier-eau de mer artificielle.

Mélange: ciment $3 /$ iaitier $=65 / 35$ (e.p.)

DRX, fraction enrichie (pâte ciment). 
(D)

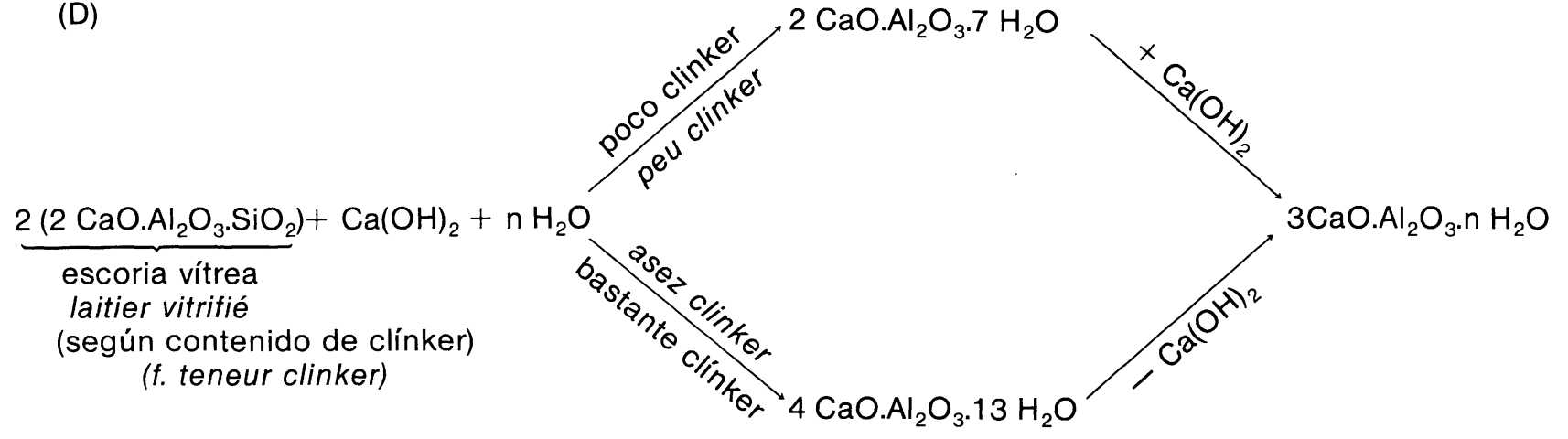

con el yeso secundario formado, como se ha señalado anteriormente, lo que hace que para un clínker y una escoria dados, las cantidades de ambos influyan en la cantidad total de ettringita formada (ettringita procedente del

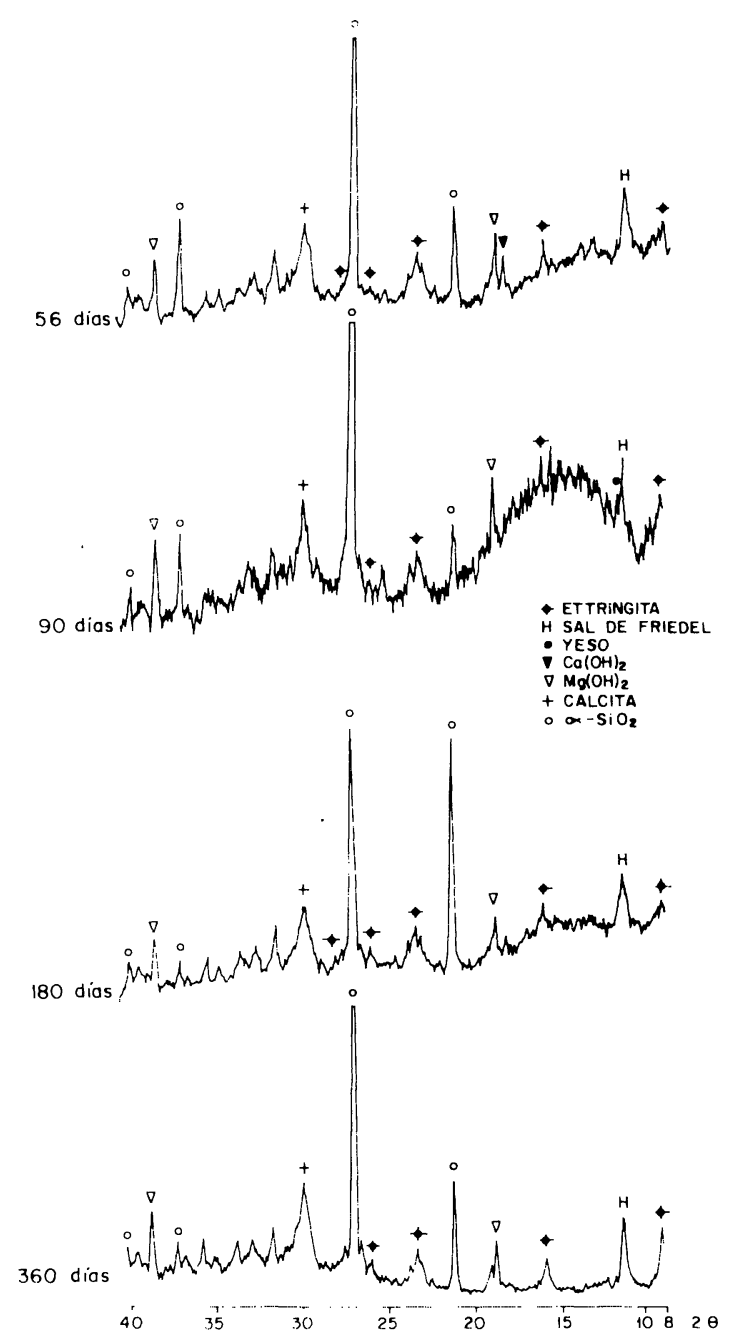

Fig. 8.4.- Sistema: cemento 3/escoria-agua de mar artificial.

Mezcla: cemento 3/escoria $=40 / 60$ (en peso).

DRX de la fracción enriquecida.

Fig. 8.4.-Système: ciment 3/laitier-eau de mer artificielle.

Mélange: ciment $3 /$ laitier $=40 / 60$ (e.p.).

$D R X$, fraction enrichie (pâte ciment). avec le gypse secondaire formé, comme il a été signalé précédemment, ce qui fait que pour un clinker et un laitier données, les quantités de tous les deux, influent sur la quantité totale d'ettringite formée (ettringitte procédant du 
clínker + ettringita procedente de la escoria), presentando a veces valores de la misma magnitud o superiores que en el caso del cemento sin adición de escoria; hecho que se ha puesto de manifiesto en este trabajo cuando se utilizan las mezclas cemento $1 \mathrm{y}$ $2 /$ escoria $=65 / 35$, en peso. Las menores cantidades, en todos los casos estudiados, corresponden a los DRX de las mezclas que tienen los mayores contenidos de escoria $(60$ y $70 \%$, que son del mismo orden.

La sal de Friedel, $3 \mathrm{CaO} \cdot \mathrm{Al}_{2} \mathrm{O}_{3} \cdot \mathrm{CaCl}_{2} \cdot 10 \mathrm{H}_{2} \mathrm{O}$, se ha producido por reacción, en medio básico, de los iones $\mathrm{Cl}$ (I) del agua de mar artificial con los iones $\mathrm{Ca}$ (II) procedentes del $\mathrm{Ca}(\mathrm{OH})_{2}$, en la interfase $\mathrm{Ca}(\mathrm{OH})_{2}$. sólido $\rightleftharpoons$ $\rightleftharpoons \mathrm{Ca}(\mathrm{OH})_{2}$.disuelto, y con el aluminato de calcio hidratado del cemento que, a su vez, puede formar ettringita con los iones $\mathrm{SO}_{4}$ (II) (9). Los iones $\mathrm{Cl}$ (I) penetran en las probetas de mortero por su gran movilidad, mayor que la de los iones $\mathrm{SO}_{4}$ (II) (10) (11) (12), facilitando la formación de la sal de Friedel; esta difusión no solo depende de la compacidad de los morteros, de la cantidad de escoria, de la relación agua/cemento, sino de la capacidad de intercambio de los sistemas (13), que es función de las características estructurales de la fracción clínker de los cementos, así como de las características y cantidad de la escoria.

En estos trabajos se ha observado que la intensidad de los picos de la sal de Friedel, en los DRX, es máxima cuando en los medios en donde han estado sumergidas las probetas el $\mathrm{pH}$ es menor de 10 y hay $\mathrm{Mg}$ (II) en cantidades menores de $3,6 \times 10^{-2}$ moles/litro; no existiendo $\mathrm{Ca}(\mathrm{OH})_{2}$ en las probetas de mortero, como sucede en las hechas con las mezclas cemento/escoria = $=65 / 35-40 / 60$ y $30 / 70$, en peso,

(de un modo especial con la primera) en donde la escoria juega un papel importante, del mismo modo que en el caso de formación de ettringita. En estos casos se pueden producir unas reacciones análogas a las mencionadas entre los aluminatos procedentes de la gehelenita de la escoria y el $\mathrm{CaCl}_{2}$ secundario, en vez del yeso secundario; reacciones que se pretende estudiar y comprobar en otros trabajos. En el caso de las probetas hechas con cemento 2 y cemento 3 , sin adición de escoria, no se han detectado los picos de la sal de Friedel.

El yeso se ha detectado en gran número de DRX; se considera que se trata de un yeso secundario, formado por reacción de los iones $\mathrm{SO}_{4}$ (II) del agua de mar

artificial con los iones $\mathrm{Ca}$ (II) del

$\mathrm{Ca}(\mathrm{OH})_{2}$ en la mencionada interfase

$\mathrm{Ca}(\mathrm{OH})_{2}$. sólido $\rightleftharpoons \mathrm{Ca}(\mathrm{OH})_{2}$.disuelta, cuando se clinker + ettringitte procédant du laitier), qui présente parfois des valeurs de la même magnitude ou supérieures que dans le cas du ciment sans addition de laitier; fait qui a été mis en évidence dans ce travail, lorsque les mélanges ciment 1 et $2 /$ laitier $=65 / 35$, en poids, sont utilisés. Les quantités plus petites, dans tous les cas étudiés, correspondent aux DRX des mélanges qui ont les teneurs en laitier les plus grands (60 et $70 \%$ ), qui sont du même ordre.

Le sel de Friedel, $3 \mathrm{CaO} \cdot \mathrm{Al}_{2} \mathrm{O}_{3} \cdot \mathrm{CaCl}_{2} 10 \mathrm{H}_{2} \mathrm{O}$, s'est produit par réaction, en solution basique, des ions $\mathrm{Cl}(\mathrm{I})$ de l'eau de mer artificielle avec les ions $\mathrm{Ca}(\mathrm{II})$ procédents du $\mathrm{Ca}(\mathrm{OH})_{2}$, dans l'interphasee $\mathrm{Ca}(\mathrm{OH})_{2}$ solide $\rightleftharpoons \mathrm{Ca}(\mathrm{OH})_{2}$ dissout, et avec l'aluminate de calcium hydraté du ciment qui, à son tour, peut former ettringite avec les ions $\mathrm{SO}_{4}$ (II) (9). Les ions $\mathrm{Cl}$ (I) pénètrent dans les éprouvettes de mortier à cause de leur grande mobilité, plus grande que celle des ions $\mathrm{SO}_{4}$ (II) (10) (11) (12), rendant plus facile la formation du sel de Friedel; cette difusion dépend non seulement de la compacité des mortiers, de la quantitié de laitier et de la relation eau/ciment, mais encore de la capacité d'échange des systèmes (13), qui est fonction des caractéristiques structurelles de la fraction clinker des ciments, ainsi que des caracteristiques et de la quantité de laitier.

Dans ces travaux il a été observé que l'intensité des pics du sel de Friedel, dans les $D R X$, est maximale lorsque, dans les solutions où les éprovettes ont été immergées, le pH est plus petite que 10 et il y a $\mathrm{Mg}$ (II) en quantités plus petites que 3,6 $610^{-2}$ moles/litre; n'ayant pas de $\mathrm{Ca}(\mathrm{OH})_{2}$ dans les éprouvettes de mortier, p.e. les fabriquées avec les mélanges ciment/laitier $=65 / 35,40 / 60$ et $30 / 70$, en poids, (surtout avec la première) où le laitier joue un rôle important, de même que dans le cas de la formation d'ettringite. Dans ces cas là il peut se produire des réactions analogues à celles déjà mentionnées entre les aluminates que precèdant de la géhélénite du laitier et le $\mathrm{CaCl}_{2}$ secondaire, au lieu de gypse secondaire; réactions que nous prétendons étudier et démontrer dans d'autres travaux. Dans les cas des éprouvettes faites avec ciment 2 et ciment 3 , sans addition de laitier, les pics de sel de Friedel n'ont pas été détectés.

Le gypse a été détécté dans un grand nombre de DRX; on considère qu'il s'agit d'un gypse secondaire, formé par réaction des ions Ca (II) du $\mathrm{Ca}(\mathrm{OH})_{2}$ dans l'interphase signalée:

$\mathrm{Ca}(\mathrm{OH})_{2}$. solide $\rightleftharpoons \mathrm{Ca}(\mathrm{OH})_{2}$. dissoute, lorsqu'on atteint le produit de solubilité

[pK $\left.\left(\mathrm{CaSO}_{4} .2 \mathrm{H}_{2} \mathrm{O}\right)=4,6\right]$. 
alcanza el producto de solubilidad

$\left[\mathrm{pK}\left(\mathrm{CaSO}_{4} .2 \mathrm{H}_{2} \mathrm{O}\right)=4,6\right]$.

El hidróxido de calcio que procede de la reacción de hidratación de la fracción clínker del cemento, únicamente, se ha detectado en los DRX de la fracción enriquecida extraída de las probetas hechas con los cementos y con las mezclas de dichos cementos con la menor cantidad de escoria (15\%), a veces con el $35 \%$ de escoria. En los casos restantes, en donde se han utilizado mayores cantidades de escoria y menores de clínker, no se ha detectado, porque ha reaccionado en estado naciente, una parte, con la escoria para dar los correspondientes compuestos de calcio y con el $\mathrm{CO}_{2}$ disuelto en el agua de mar, por otra, para formar calcita en la probeta; el resto se ha disuelto en el agua de mar.

En todos los DRX se han detectado los picos de la calcita y de la brucita; la calcita se ha formado por reacción, en medio básico fuerte, del $\mathrm{CO}_{2}$ disuelto en el agua de mar artificial con el $\mathrm{Ca}$ (II) del $\mathrm{Ca}(\mathrm{OH})_{2}$ presente en la pasta de cemento y la brucita por reacción del $\mathrm{Mg}$ (II) del agua de mar artificial con los iones $\mathrm{OH}$ (I) del $\mathrm{Ca}(\mathrm{OH})_{2}$ que existe en la pasta de cemento - por alcanzarse los productos de solubilidad del $\mathrm{CaCO}_{3}\left(\mathrm{P}^{\prime} \mathrm{s}=4,8 \times 10^{-9}\right.$ ) y del $\mathrm{Mg}(\mathrm{OH})_{2}\left(\mathrm{Ps}=1,8 \times 10^{-11}\right)$ - según las reacciones $(C)$ y $(B)$, respectivamente. En estas reacciones también influyen, como en los casos anteriores, el grado de difusión del $\mathrm{CO}_{2}\left[\mathrm{CO}_{2}+2 \mathrm{OH}(\mathrm{I}) \rightleftharpoons \mathrm{CO}_{3}(\mathrm{II})+2 \mathrm{H}(\mathrm{I})\right]$ y de los iones $\mathrm{Mg}$ (II) en las probetas de mortero, que depende de la compacidad de dichas probetas y de la cantidad de escoria en las mezclas cemento/escoria. Las mayores cantidades de brucita corresponden a las series de probetas de mortero hechas con las mezclas cemento/escoria $=65 / 35$, en peso.

\section{CONCLUSIONES}

\section{Primera}

En los sistemas cemento (1, 2 y 3$)$ /escoriaagua de mar artificial aparece una nueva fase sólida que está formada por los compuestos cristalinos calcita (en todos los casos estudiados), aragonito (prácticamente, en todos los casos) y brucita (en los medios en donde han estado sumergidas las probetas hechas con cemento y con la mezcla cemento/escoria $=85 / 15$, en peso) .

\section{Segunda}

La composición estructural de la nueva fase sólida depende de la mezcla (cemento/escoria)
L'hydroxide de calcium provenant de la réaction d'hydratation de la fraction clinker $d u$ ciment a été uniquement détecté dans les DRX de la fraction enrichie extraite des éprouvettes fabriquées avec les ciments et avec les mélanges de ces ciments avec la plus petite quantité de laitier (15\%), parfois avec $35 \%$ de laitier. Dans le reste des cas, avec les plus grandes quantités de laitier et les plus petites de clinker ils sont utilisées, il n'a pas été détecté parcequ'il a réactionné dès la naissance, d'une part, avec le laitier pour donner les composants de calcium correspondants et avec le $\mathrm{CO}_{2}$ dissout dans l'eau de mer, de l'autre, pour former calcite en éprouvette, le reste s'est dissout dans l'eau de mer.

Dans tous les $D R X$ nous avons détecté les pics de la calcite et de la brucite; la calcite s'est formée par réaction, en solution basique forte, du $\mathrm{CO}_{2}$ dissout dans l'eau de mer artificielle avec le $\mathrm{Ca}(\mathrm{II})$ du $\mathrm{Ca}(\mathrm{OH})_{2}$ présent dans la pâte de ciment et la brucite par réaction de $\mathrm{Mg}$ (II) de l'eau de mer artificielle avec les ions $\mathrm{OH}$ (I) de $\mathrm{Ca}(\mathrm{OH})_{2}$ existant dans la pâte de ciment - pour atteindre les produits de solubilité $d u$ $\mathrm{CaCO}_{3}\left(P^{\prime} \mathrm{s}=4,8 \times 10^{-9}\right)$ et du $\mathrm{Mg}(\mathrm{OH})_{2}$ $\left(P s=1,8 \times 10^{-11}\right)$ - d'après les réactions $(C)$ et $(B)$, respectivement. Dans ces réactions le degré de diffusion du $\mathrm{CO}_{2} \mathrm{CCO}_{2}+2 \mathrm{OH}(\mathrm{I}) \rightleftharpoons$ $\left.\rightleftharpoons \mathrm{CO}_{3}(\mathrm{II})+2 \mathrm{H}(\mathrm{I})\right]$ et des ions $\mathrm{Mg}(\mathrm{II})$, a aussi une influence sur les éprouvettes de mortier qui dépend de la compacité de ces éprouvettes et de la quantité de laitier dans les mélanges ciment/laitier. Les plus grandes quantités de brucite correspondent aux séries d'éprouvettes de mortier faites avec les mélanges ciment/laitier $=65 / 35$, en poids.

\section{CONCLUSIONS}

\section{Première:}

Dans les systèmes ciment (1,2 et 3)/laitier-eau de mer artificielle apparaît une nouvelle phase solide qui est formée par les composants cristallins calcite (dans tous les cas étudiés), aragonite (pratiquement dans tous les cas) et brucite (dans les solutions où ont été immergées les éprouvettes fabriquées avec ciment et avec le mélange ciment/laitier = $=85 / 15$, en poids).

\section{Deuxième}

La composition structurelle de la nouvelle phase solide dépend du mélange 
utilizada en la fabricación de las probetas de mortero, que influye en las características del agua de mar artificial en donde han estado sumergidas $[\mathrm{pH}$; concentración de $\mathrm{Ca}$ (II) y $\mathrm{Mg}$ (II), fundamentalmente; cantidad de fase sólida, etc.] y que, a su vez, favorece la formación de unos $u$ otros compuestos.

\section{Tercera}

En los DRX de las diversas fracciones enriquecidas se han identificado los picos de la brucita, ettringita y calcita, en todos ellos, y los de la sal de Friedel, yeso y portlandita, en parte, con intensidad variable, que depende de la mezcla utilizada en la fabricación de las probetas de mortero y del tiempo de coservación-ataque.

\section{Cuarta}

La adición de escoria a los cementos influye en la composición estructural de la fracción enriquecida (cemento hidratado-atacado) extraída de las probetas de mortero fabricadas con dichas mezclas, sometidas a la acción del agua de mar artificial.

\section{Quinta}

La mayor intensidad de los picos de la ettringita, de la sal de Friedel (por regla general) y de la brucita corresponde a los DRX de las fracciones enriquecidas (cemento hidratado-atacado) extraidas de las probetas hechas con las mezclas cemento/escoria = $=63 / 35$, en peso. (ciment/laitier) employé dans la fabrication des éprouvettes de mortier, qui influe sur les caractéristiques de l'eau de mer artificielle où les éprouvettes ont été immergées $[\mathrm{pH}$; concentration de $\mathrm{Ca}$ (II) et $\mathrm{Mg}$ (II), fondamentalement; quantité de phase solide, etc.] et qui, à son tour, favorise la formation des uns et des autres composants.

\section{Troisième}

Dans tous les DRX des différentes fractions enrichies les pics de la brucite, l'ettringite et la calcite ont été identifiés et ceux du sel de Friedel, gypse et portlandite, en partie et avec une intensité variable qui dépend du mélange employé pour l'élaboration des éprouvettes de mortier et du temps de conservation-attaque.

\section{Quatrième}

L'addition de laitier aux ciments influe sur la composition structurelle de la fraction enrichie (ciment hydraté-attaqué) extraite des éprouvettes de mortier elaborées avec ces mélanges, soumises à l'action de l'eau de mer artificielle.

\section{Cinquième}

L'intensité la plus élevée des pics d'ettringite, de sel de Friedel (en règle générale) et de brucite correspond aux DRX des fractions enrichies (ciment hydraté-attaqué) extraites des éprouvettes élaborées avec les mélanges ciment/laitier $=65 / 35$ en poids.

\section{BIBLIOGRAFIA}

\section{BIBLIOGRAPHIE}

(1) GASPAR-TEBAR, D.; SAGRERA-MORENO, J. L. y GONZALEZ-VILA, V. (1985): Contribución al estudio de la resistencia química de los cementos. Comportamiento mecánico de un cemento portland resistente al yeso (1.a parte). Materiales de Construcción; abril, mayo, junio, 198, 31-41.

(2) GASPAR-TEBAR, D.; SAGRERA-MORENO, J. L. y GONZALEZ-VILA, V. (1985): Contribución al estudio de la resistencia química de los cementos. Comportamiento mecánico de un cemento portland resistente al yeso $\left(2 .^{a}\right.$ parte). Materiales de Construcción; octubre, noviembre, diciembre, 200, 49-66.

(3) GASPAR-TEBAR, D. et SAGRERA-MORENO, J. L. (1987): L'action de l'eau de mer sur un ciment portland à haute résistance initiale et sur un ciment portland résistant aux sulfates: influence de l'addition de laitier. Etude de la concentration ionique. Materiales de Construcción; abril, mayo, junio, 206, 27-42.

(4) GASPAR-TEBAR, D.; SAGRERA-MORENO, J. L. y BERMEJO-MUÑOZ, M. ${ }^{a}$ F. (1981): Resistencia química del hormigón: IX. Contribución al estudio del sistema: cemento P-450-Y hidratado-agua desionizada. Materiales de Construcción; julio, agosto, septiembre, 183, 17-30.

(5) BERMEJO-MUÑOZ, M. ${ }^{a}$ F.; SAGRERA-MORENO, J. L. y GASPAR-TEBAR, D. (1981): Resistencia quimica del hormigón: XIII. Contribución al estudio del sistema: cemento P-450-Y-disolución de sulfato de sodio. Materiales de Construcción; octubre, noviembre, diciembre, 184, 51-63.

(6) GASPAR-TEBAR, D.; SAGRERA-MORENO, J. L. y BERMEJO-MUÑOZ, M. ${ }^{a}$ F. (1981): Resistencia química del hormigón: XIV. Contribución al estudio del sistema: cemento P-450-Y-disolución de sulfato de magnesio. Materiales de Construcción; octubre, noviembre, diciembre, 184, 65-82. 
(7) GARCIA DE PAREDES, P. (1967): Inalterabilidad de los conglomerantes frente al ataque de los sulfatos. Comparación de mëtodos de apreciarla. Cuadernos de Investigación del IETcc (Madrid); págs. 11-14.

(8) CHARLOT, G. (1963): L'Analyse Qualitative et les Réactions en solution. Edit. Masson et Cie; Paris, pages $213-214$.

(9) KALOUSEK, G. L. and BENTON, E. J. (1970): Mechanism of sea water Attack on Cement Pastes. Journal ACI, Title n. 67-9, págs. 187-191.

(10) REGOURD, M.; HORNAIN, H. et MORTUREUX, B. (1974): Influence du mode de cristallisation de l'aluminate tricalcique sur la resistance des ciments à l'eau de mer. Revue des Matériaux de Construction, 687, pág. 72.

(11) REGOURD, M. (1975): L'action de l'eau de mer sur les ciments; Annales de l'Institut Technique du Bâtiment et des Travaux Publics (Serie: Liants Hydrauliques; n.²5), 329, pág. 95.

(12) ONO, M.; NAGASSHIMA, M.; OTSUKA, K. and ITO, T. (1978): Some aspects of the Mechanism of Sea Water Attack on the hardened Cement Pastes; Rev. of the Thirysecond Gen. Meeting; Technical Session-Held in Tokyo, págs. 59-60.

(13) GJÖRV, O. E. and VENNESLAND, O. (1979): Diffusion of Chloride ions from sea water into concrete. Cement and Concrete, 2, 229-238.

\section{RECONOCIMIENTOS}

Nuestro más sincero reconocimiento a las personas del Equipo de Durabilidad del IETcc: Amalia Rodríguez Pereíra, Lucila López Solana, M. ${ }^{\mathrm{a}}$ Soledad Cid Fernández, Felipe Cantero Palacios y Manuel Cantero Palacios por su valiosa colaboración en la realización de este trabajo.

\section{REMERCIEMENTS}

Nous voudrons exprimer nôtre plus vive reconnaissance aux membres de l'El "Durabilidad" de l'IETcc: Amalia Rodríguez Pereíra, Lucila López Solana, M. ${ }^{a}$ Soledad Cid Fernández, Felipe Cantero Palacios y Manuel Cantero Palacios pour l'aide prêtée dans la réalisation de ce travail.

\section{publicación del i.e.t.c.c.}

\begin{tabular}{|c|c|}
\hline 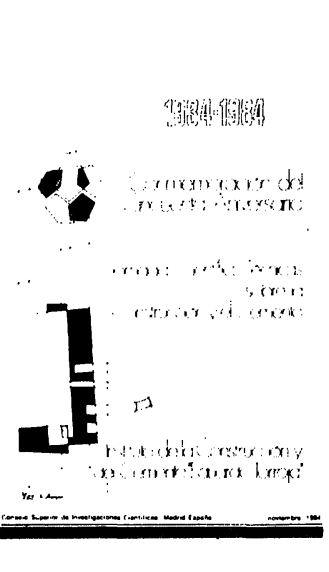 & $\begin{array}{l}\text { Jornadas Científico-Técnicas } \\
\text { sobre la Construcción y el Cemento } \\
\text { En un deseo de informar eficazmente sobre la situación actual en el campo de la } \\
\text { Construcción y del Cemento, los investigadores y técnicos agruparon sus exposicio- } \\
\text { nes en los siguientes tres grandes temas: Materiales de Construcción, Tecnología de } \\
\text { la Construcción, y Normativa-Calidad-Cooperación. Se consiguió de esta manera pre- } \\
\text { sentar una panorámica real de la Investigación y Desarrollo en la materia. } \\
\text { Consideramos que el libro es de interés para cuantos siguen la evolución de la Cons- } \\
\text { trucción en general y que en muchos casos encontrarán estudios, en profundidad, de } \\
\text { temas y problemas puntuales. } \\
\text { Esta obra se publicó con motivo de la celebración de las Bodas de Oro del Instituto } \\
\text { Eduardo Torroja - Noviembre } 1984 \text { y en sus } 283 \text { páginas se recogen, de forma crono- } \\
\text { lógica, las } 35 \text { intervenciones, conferencias y comunicaciones de los numerosos espe- } \\
\text { cialistas - nacionales y extranjeros- que tomaron parte. }\end{array}$ \\
\hline
\end{tabular}

